Nip, K. H., Gardner, L. and Elghazouli, A. Y. (2013). Ultimate behaviour of steel braces under cyclic loading. Proceedings of the Institution of Civil Engineers - Structures and Buildings. 166(5), 219-234.

\title{
Ultimate behaviour of steel braces under cyclic loading
}

\author{
K.H. Nip, L. Gardner and A. Y. Elghazouli
}

\begin{abstract}
Under significant seismic loading conditions, the response of concentrically braced frames largely depends on the behaviour of the diagonal braces, which represent the key energy dissipating zones. Although the hysteretic response of steel braces under cyclic axial loading has been examined in previous studies, there is a need for further assessments which focuses on quantifying failure. This paper describes the development of detailed finite element models of hollow sections subjected to cyclic axial loading. The effects of initial imperfections and cyclic hardening are taken into consideration and the models are validated against data from 19 tests. A method to predict the fracture life of bracing members under cyclic loading is also described. Using the numerical models, parametric studies are undertaken to assess the influence of global and local slendernesses on the performance of the braces - both are found to affect the occurrence and severity of local buckling under cyclic loading, which causes high localised strains at the corner areas of sections leading to fatigue fracture. A predictive equation addressing the co-existing influence of global slenderness and local slenderness on displacement ductility is presented. The observations in the current study are compared with the conclusions from other experimental programmes and the discrepancy between the findings is discussed.
\end{abstract}

\section{Notation:}
A
Cross-sectional area
b Width of the flat area of the longer face of a hollow section
c Fatigue ductility exponent
$\mathrm{C}_{\mathrm{s}} \quad$ Empirical constant
d Width of the flat area of the shorter face of a hollow section
D Damage index 


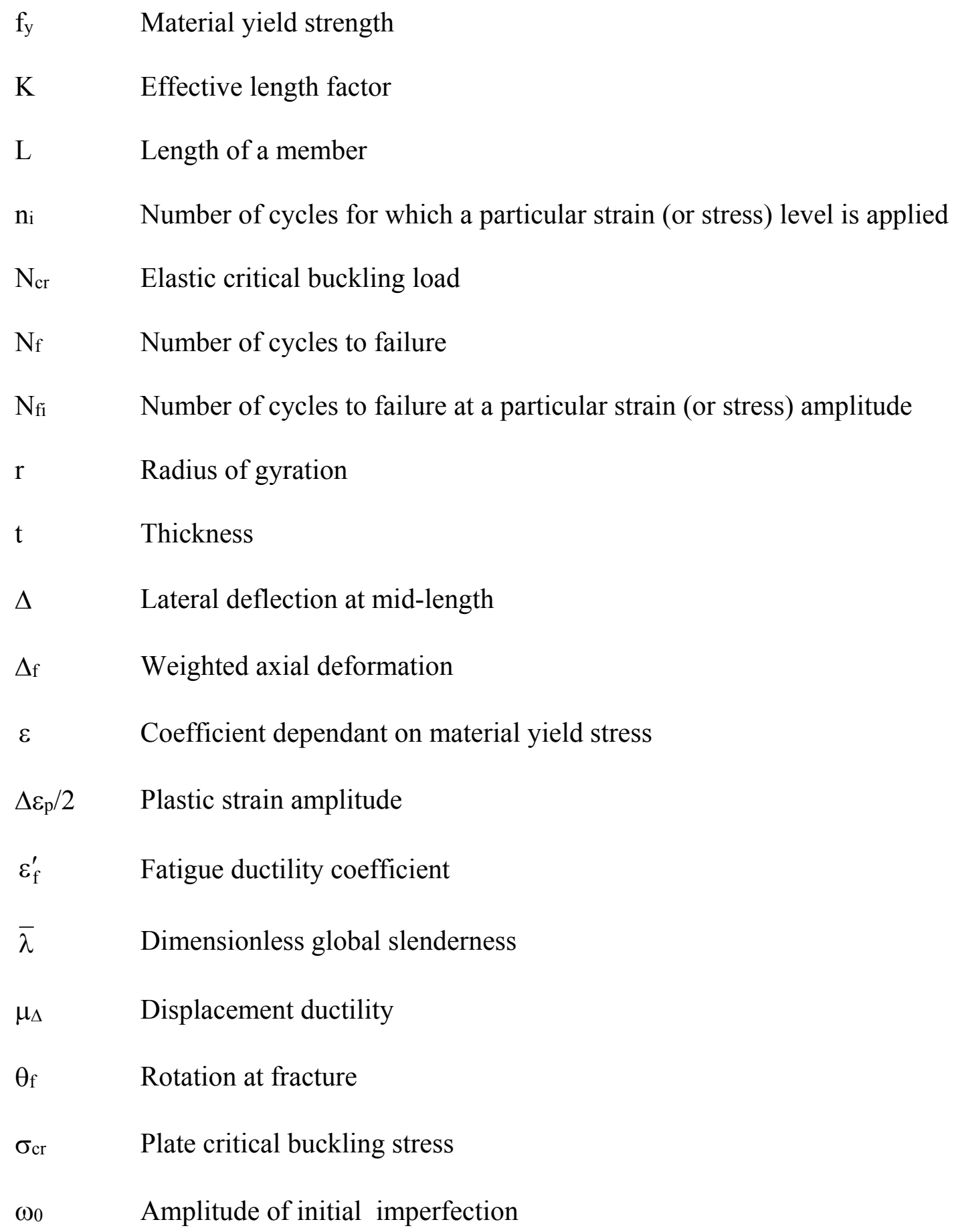

Keywords: buildings, structures \& design, fatigue, steel structures 


\title{
Ultimate behaviour of steel braces under cyclic loading
}

\author{
K.H. Nip, L. Gardner and A.Y. Elghazouli \\ Imperial College London, U.K.
}

\section{$1 \quad$ Introduction}

Satisfactory behaviour of structures under severe seismic loading is largely dependent on the ability of key components to undergo significant inelastic deformations. In the case of braced frames, the critical elements are the diagonal bracing members which are expected to experience repeated cycles involving yielding in tension and member buckling in compression (Elghazouli, 2003). In addition to the cyclic response of the braces, it is imperative to understand and quantify the ductility and associated failure criteria, which involve interactions between global and local effects in these members. Whilst many earlier studies have examined the hysteretic response of bracing members, comparatively less attention has been given to the ultimate behaviour and failure conditions.

The cyclic response of steel bracing members has been examined previously by many researchers. For example, an early study of the hysteretic behaviour of steel braces was conducted by Popov et al. (1979). Circular hollow sections (CHS) with various end conditions as well as different global and local slendernesses were tested. Linearised hysteresis loops for computer analysis were proposed. Jain et al. (1980) also carried out cyclic axial tests on square hollow section (SHS), rectangular hollow 
section (RHS) and angle members. A phenomenological cyclic model was proposed and it was concluded that global slenderness is the most important parameter influencing the hysteretic behaviour. A later study by Walpole (1996), involving cyclic axial tests on RHS with both pin-ended and fixed-ended conditions, resulted in the development of theoretical models to capture the hysteretic response of the test specimens. In a more recent study focusing on the effect of local slenderness, Han et al. (2007) tested SHS in a braced frame. The occurrence of global buckling, local buckling and fracture of SHS with varying slenderness was reported.

A comprehensive survey of the experimental cyclic behaviour of steel bracing members was conducted by Tremblay (2002). Buckling and post-buckling resistance in compression, capacity in tension, and a number of other properties from about 50 members were assessed, and formulae for predicting several response parameters were proposed. From the range of available data, it was indicated that the fracture life of a bracing member depends more strongly on the global slenderness than the local slenderness. This conclusion was supported by Elchalakani et al. (2003) based on the results of tests on CHS. It was also noted in this study that the influence of the number of cycles at a constant displacement amplitude on ductility is significant, but has only a minor effect on the ultimate compressive strength.

Other studies that have addressed the influence of brace slenderness include that of Shaback and Brown (2003) which involved tests on SHS members with gusset plate end connections. Empirical formulae were proposed to predict the fracture life of SHS braces in terms of global slenderness and local slenderness, among other parameters. Similarly, Goggins et al. (2006) carried out cyclic axial tests on SHS and RHS 
members. The influence of yield strength and global and local slendernesses on the displacement ductility capacity was studied. Based on the experimental results, relationships between ductility and slenderness parameters were proposed. Rotation at fracture was also employed as an alternative measure of member ductility (Tremblay et al., 2003).

In order to understand the interaction between the bracing members and connections, Yoo et al. (2008) tested full-scale frames resembling a braced bay of one storey of a building. The frames were subjected to a cyclic inelastic deformation history. Buckling occurred in the square hollow section bracing members as loading increased. The braces ultimately failed by initiation of cracks and subsequent fracture at midheight. Finite element models were developed to simulate the braced frames. The output values of equivalent plastic strain were used as an indicator for predicting fracture. When the equivalent plastic strain exceeded a threshold value, a crack was assumed to have initiated. This approach required specific calibration for different structural systems and sections since the value of the threshold level depended on the finite element type and mesh size.

With an emphasis on understanding the fracture of braces under seismic loading, Fell et al. (2009) conducted 18 cyclic tests on square hollow section, circular hollow section and I-section members. It was observed that bracing members with high local slenderness were more prone to local buckling and fracture initiation. The effect of global slenderness on the fracture life of braces was not clearly demonstrated by the tests, since the tested global slenderness range was rather limited. 
Previous experimental studies and the semi-empirical rules arising from these investigations suggest that fracture lives of bracing members depend to a varying degree on global slenderness, local slenderness, cross-section proportions and material strength. Despite the availability of a number of models for predicting the ductility capacity of braces, there are significant uncertainties in these predictions owing to their semi-empirical nature as well as the scatter of test results. More importantly, due to physical limitations in laboratory testing, experimental studies cover a limited range of member sizes and lengths, and the influences of local and global slenderness are often difficult to quantify in isolation.

This paper examines the cyclic performance of hollow steel bracing members with emphasis on the ultimate behaviour and failure conditions. Detailed three-dimensional finite element models of typical bracing members have been developed. They have been used instead of phenomenological models as they are able to simulate not only global behaviour, but also local buckling and cross-section deformation. Results from the numerical models have been used in conjunction with a failure prediction approach to quantify the fracture life of bracing members. The models were validated against experimental results on braces of hot-rolled carbon steel, cold-formed carbon steel and cold-formed stainless steel, and subsequently used to conduct a number of parametric investigations to assess the influence of key parameters including the relative importance of local and global slenderness.

\section{Development of FE models}




\section{$2.1 \quad$ General}

The general purpose finite element (FE) package ABAQUS (2007) was used to develop models to replicate cyclic loading tests on SHS and RHS braces. The models were subjected to cyclic axial displacements with large plastic deformation within non-linear analyses. The numerical results were initially validated against tests, after which, a series of parametric studies were performed.

\subsection{Element type and mesh size}

The 4-node doubly curved general-purpose shell element with reduced integration, designated S4R (ABAQUS, 2007), was employed throughout the study. This element allows transverse shear deformation and can be used for thick or thin shell applications. It has been used in previous studies for modelling hollow section columns and has produced accurate results for compressive resistance and failure modes (Ellobody and Young, 2005, Chan and Gardner, 2009).

Strain outputs from the models were found to be sensitive to mesh size. In order to improve computational efficiency, varying mesh densities were employed in different areas in the models. Refined meshes were used only in areas where local buckling was anticipated, i.e. at the mid-length and ends of the members, since all braces were fixed-ended. The fine mesh at the end of the braces was required to capture the location and shape of local buckling accurately but no strain outputs from that part were used for predicting fracture. Mesh sensitivity studies also indicated that the demand for the fineness of the mesh at each end of the braces was lower than at mid- 
length and therefore a less refined mesh was used. The extent of the refined mesh in the longitudinal direction was set to 1.5 times the dimension of the larger face of the section. This ensured that the refined area was sufficiently large to accommodate the half wavelength of the locally buckled shape, which was approximately equal to the dimension of the larger face of the section. Two lines of symmetry were also utilised in the current models such that only one quarter of the members were modelled, as depicted in Figure 1.

The size of the elements in the refined mesh was chosen by means of a convergence study. The convergence study was carried out on a $40 \times 40 \times 2.5$ member $(1100 \mathrm{~mm}$ in length) under monotonically increasing compressive load. For the reasons outlined in Section 2.6, both the peak strains of a single element and the average strains over a fixed area at the corner of the section at mid-span were recorded and compared at various levels of lateral displacement. It was observed that the local buckling resistance and deformed shape were both influenced by mesh size. A finer mesh, which more closely resembles a continuum, is less stiff and therefore is more prone to buckling than a coarse mesh. Moreover, a finer mesh allows high localised peak strains to be recorded, in contrast to a coarser mesh that would provide lower, more uniform, strains over a larger area. As anticipated, the strain outputs were found to increase as the element size decreased (Figures 2 and 3) and since the variation in strain output was small beyond a mesh size of 32 elements per face, this mesh size was adopted for the remainder of the study.

\subsection{Material modelling}


The investigated specimens were subjected to large plastic strains and load reversals. A material model capable of simulating cyclic material properties such as the Bauschinger effect and expansion of the elastic material range was needed. The nonlinear isotropic/kinematic hardening model in ABAQUS (2007) was adopted in the FE models in the current study. A series of large amplitude strain-controlled fullyreversed cyclic axial material tests was carried out on coupons cut from the flat faces of square and rectangular hollow section members to calibrate the material cyclic hardening model. Brace specimens from the same batch of material were also tested under cyclic loading, providing the data against which the FE models were validated. Details of the calibration process and a quantitative description of the cyclic material parameters have been reported by Nip et al. (2010a).

The strength enhancement in the corner regions of the cold-formed sections was also considered. In the nonlinear isotropic/kinematic hardening model, the yield strength of the corner materials was increased by the same proportion as that observed in the tensile coupon tests on the flat and corner materials of the hollow section members. The strength enhancement was assumed to extend beyond the corner to a distance equal to one times the material thickness for the cold-formed carbon steel models (Karren, 1967) and two times the material thickness for the cold-formed stainless steel models (Ashraf et al., 2005, Cruise and Gardner, 2008). Homogeneous material properties around the section were assumed for the hot-rolled carbon steel models.

Residual stress magnitudes in hot-rolled and cold-formed hollow section members lie typically within the elastic range of the material (Gardner et al., 2010). Low cycle fatigue, as experienced in bracing members under seismic conditions, involves large 
plastic deformations and strains. Such plastic deformation would swamp any influence from initial residual stresses; hence residual stresses have not been included in the finite element models.

\subsection{Boundary conditions and displacement history}

Boundary conditions were applied to the numerical models to represent the fixed end conditions of the test specimens. All degrees of freedom of nodes at both ends of the members were restrained, except for axial displacement at the loaded end. The braces were analysed under displacement control. The applied axial displacement history followed the recommendations of ECCS (1986), i.e. one cycle at each level of 0.25 , $0.5,0.75$ and $1.0 \delta_{\mathrm{y}}$, followed by three cycles at each level of $2,4,6,8 \delta_{\mathrm{y}}$, etc. where $\delta_{\mathrm{y}}$ is the estimated axial yield displacement.

\subsection{Initial imperfections}

All structural members contain initial geometric imperfections. These imperfections trigger out-of-plane deflections at stresses below the theoretical critical buckling values. In this study, both global and local initial geometric imperfections were incorporated into the numerical models to assess their influence.

The effect of global imperfection amplitude on the buckling of tubular columns under ambient and fire scenarios has been examined numerically in previous studies (Gardner and Nethercot, 2004, Ng and Gardner, 2007). The results of these studies have indicated that buckling loads were relatively insensitive to variation in 
imperfection amplitudes below about L/1000, where L is the column length, with an amplitude of $\mathrm{L} / 2000$ providing the best prediction of test behaviour.

For local imperfections, Gardner and Nethercot (2004) calibrated the predictive formula proposed by Dawson and Walker (1972) for stainless steel specimens and gave the following expression:

$$
\omega_{0} / \mathrm{t}=0.023\left(\mathrm{f}_{\mathrm{y}} / \sigma_{\mathrm{cr}}\right)
$$

where $\omega_{0}$ is the initial imperfection amplitude, $t$ is the plate thickness, $f_{y}$ is the material yield stress and $\sigma_{\mathrm{cr}}$ is the plate critical buckling stress. Gardner et al. (2010) also measured local imperfections in the carbon steel specimens examined in this study and other similar specimens. A least-squares regression analysis of the measured imperfection data for cold-formed and hot-rolled hollow sections resulted in the proposal of the predictive expressions given by Equations 2 and 3 respectively. These are based on a second Dawson and Walker (1972) model in which the ratio of $\mathrm{f}_{\mathrm{y}} / \sigma_{\mathrm{cr}}$ is raised to the power of 0.5 .

$$
\begin{aligned}
& \omega_{0} / t=0.034\left(f_{y} / \sigma_{c r}\right)^{0.5} \\
& \omega_{0} / t=0.028\left(f_{y} / \sigma_{c r}\right)^{0.5}
\end{aligned}
$$

A sensitivity study was conducted to assess the response of the models to variation in global and local imperfections. The amplitude of the local imperfection was varied from $t / 10$ to $t / 1000$ while that of the global imperfection was varied from $L / 100$ to L/10000. As in previous research (Gardner and Nethercot, 2004, Ng and Gardner, 2007), the maximum compressive resistances of the braces were found to be relatively insensitive to variation in global imperfection amplitude below about L/1000. The 
study also showed that larger amplitudes of local imperfection (and to a lesser extent global imperfection) caused earlier local buckling but the effect on fracture was small. It was found that varying the amplitude of either global or local imperfection by a factor of 100 generally only resulted in a difference of 2 or fewer cycles to fracture, which was estimated by a strain-based damage prediction method described in Section 3 .

Global imperfections with an amplitude of L/1500 were employed for the remainder of the study. Local geometric imperfections comprising longitudinal sinusoidal waves with half-wavelengths equal to the width of the section and compatible sinusoidal half-waves across the section faces were introduced into the numerical models (Figure 4). The amplitudes of the local imperfections followed the values given by Equations 1-3. The global imperfections were incorporated into the models by applying an equivalent load at mid-length while the local imperfections were included by defining nodes directly in their imperfect configuration.

\subsection{Output of strains}

Assessment of strains was central to the parametric studies, enabling prediction of fatigue fracture from a strain-life relationship. There were a number of factors to consider when extracting strains from the numerical models, including the measure of strain, the location of strain output and through-thickness effects. These factors are discussed below. 
ABAQUS offers a number of different measures and components of strain output. The discrepancy between different strain measures can become significant when the strain is large. The total strain designated E, which is the sum of the elastic and plastic strains, was adopted and examined in this study, since this is the strain measure upon which the utilised strain-life relationships were based (see Section 3.2).

In general, strains may be extracted either from a single element or from a group of adjacent elements. Output from a single element can capture the peak strain from the most critical location but is sensitive to changes in mesh size. In contrast, strains averaged over a constant area are less sensitive to the mesh size, but the extent of the chosen measurement area requires careful consideration. In this study, the measurement area was selected such that it was sufficiently small to avoid diluting the peak strains by the results of elements remote from the peaks but large enough to be insensitive to mesh size. From the models, it was observed that the highest strains occurred at the corners and around the middle eighth of the buckling wave in the longitudinal direction (see Figures 5 and 6). Furthermore, experimental evidence has shown that the ductility of the corner material of cold-formed sections is lower than that of the flat material due to work-hardening and that fracture generally initiates at the corners. Average strains over an area covering the corner and one-eighth of the buckling wavelength were therefore used to predict damage and calculate fatigue life. For comparison, the results form both the peak strain values from a single element and the average values of the elements over a constant area are presented and examined later in this paper. 
The S4R element has five integration points (by default) through the thickness, from which strain readings may be taken. Strains vary through the thickness due to local bending. In this paper, the points on the outer and inner surfaces of a section are referred to as SPOS and SNEG respectively. Output of strains based on SPOS consistently yields the largest strain amplitudes. However, prediction of fatigue lives from these strain amplitudes alone would overestimate the damage since this maximum value would be assumed constant through the thickness. Conversely, using the average of SPOS and SNEG would underestimate the damage since the effect of local bending would be ignored. Therefore, fatigue lives calculated on the basis of the SPOS strains and on the average of the two surfaces can be assumed to result in lower and upper bounds.

From the combination of areas considered and surfaces from which strain output may be taken, four cases arise: (1) SP-avg (average strains over the corner area based on SPOS), (2) SPN-avg (average strains over the corner area based on (SPOS+SNEG)/2), (3) SP-peak (peak strains from a single element based on SPOS), and (4) SPN-peak (peak strains from a single element based on (SPOS+SNEG)/2).

\section{$3 \quad$ Damage prediction}

\subsection{Overview}

The bracing members examined in the current study were subjected to large cyclic displacements, resulting in high localised plastic deformation which would, in reality, 
lead to fatigue failure. Fatigue due to such high plastic deformation is considered as low cycle fatigue, or sometimes referred to as ultra low cycle fatigue for failure in less than 20 cycles. Various techniques have been developed to simulate and predict fracture in steels. Fracture mechanics approaches such as the J-integral (Rice, 1968) have are limited essentially to situations where yielding is localised at a crack tip. In case of the current study, the widespread plastic deformation at areas of local buckling violates this crucial assumption so this approach is not applicable. Micromechanicsbased models developed by Kanvinde et al. (2008) predict fracture by considering local stresses and strains. This approach is suitable for ductile fracture initiation but it cannot be applied to cyclic loading. When adopting these approaches in FE models, extremely fine mesh sizes are required at areas where cracks initiate.

This paper introduces a fracture prediction approach which allows the use of finite element models with relatively coarse meshes and is applicable to structural members subjected to cyclic loading. This approach allows the simulation of structural phenomena, such as global and local buckling of a member, as well as the prediction of fatigue fracture, in the same model. A strain-based approach, which utilises strain output in conjunction with strain-life models of the material, is deemed most suitable for this purpose.

The adopted procedure for predicting damage first requires the monitoring of strains during each cycle of loading. A fatigue life is then obtained through the CoffinManson (Coffin, 1954, Manson, 1954) relationship, calibrated for the material being studied. Finally, the damage caused by each cycle is accumulated by means of 
Miner's (1945) rule and fracture is predicted from this damage value. Details of these steps are given in the following sub-sections.

\subsection{Strain-life relationship}

It has been observed that plastic strain-life data from low cycle fatigue tests fall approximately on a straight line when plotted on a log-log scale. This observation forms the basis of the Coffin-Manson (Coffin, 1954, Manson, 1954) relationship, which is expressed as:

$$
\frac{\Delta \varepsilon_{\mathrm{p}}}{2}=\varepsilon_{\mathrm{f}}^{\prime}\left(2 \mathrm{~N}_{\mathrm{f}}\right)^{\mathrm{c}}
$$

where $\Delta \varepsilon_{\mathrm{p}} / 2$ is the plastic strain amplitude, $\varepsilon_{\mathrm{f}}^{\prime}$ is the fatigue ductility coefficient, $\mathrm{c}$ is the fatigue ductility exponent and $2 \mathrm{~N}_{\mathrm{f}}$ is the number of reversals to failure.

Based on constant strain amplitude cyclic material tests at $\pm 1 \%, \pm 3 \%, \pm 5 \%$ and $\pm 7 \%$ total strain amplitudes, the Coffin-Manson relationships for each of hot-rolled carbon steel, cold-formed carbon steel and cold-formed stainless steel have been calibrated and reported by Nip et al. (2010a) (Figure 7). Strain amplitudes from the critical areas of the models (i.e. the corner regions adjacent to the location of local buckling) can be input into Equation 4 to give the corresponding fatigue lives.

\subsection{Variable amplitude loading}


The strain-life relationship outlined above applies to constant-amplitude fatigue test data. In the present study, however, strain amplitudes experienced by the members varied from cycle to cycle due to the variable displacement history and changes in the buckling shape. Therefore, a fatigue life corresponding to the strain amplitude in each cycle was calculated and the combined effects of these cycles were assessed through a cumulative damage rule. A conventional form of cumulative damage model is the linear Miner's (1945) rule:

$$
\mathrm{D}=\sum_{\mathrm{i}=1}^{\mathrm{n}} \frac{\mathrm{n}_{\mathrm{i}}}{\mathrm{N}_{\mathrm{fi}}}
$$

where $\mathrm{N}_{\mathrm{fi}}$ is the number of cycles to failure at a strain (or stress) level of $\varepsilon_{\mathrm{i}}$ (or $\sigma_{\mathrm{i}}$ ) and $\mathrm{n}_{\mathrm{i}}$ is the number of cycles for which that particular strain (or stress) level is applied. Fatigue occurs when the damage index, D, reaches unity. Equation 5 was adopted in this study.

\section{$4 \quad$ Verification of FE models and results of parametric studies}

\subsection{Verification of FE models}

Prior to performing parametric studies, the FE models were verified against cyclic axial loading tests on hot-rolled carbon steel, cold-formed carbon steel and coldformed stainless steel hollow sections (Nip et al., 2010b). The basic measured tensile mechanical properties of the materials of the specimens tested are given in Table 1. In Table 1, and throughout the paper, specimens are identified by specimen size (depth $\times$ width $\times$ thickness $\times$ length), material (either carbon steel ' $\mathrm{CS}$ ' or stainless steel 'SS') 
and forming process (either hot-rolled 'HR' or cold-formed 'CF'), with the specimen length omitted if not applicable. A number of other available experiments performed on members in a similar configuration were also considered (Walpole, 1996, Goggins et al., 2006). Among the tests of Walpole (1996), only the one carried out with fixed end conditions was employed for verification $(150 \times 100 \times 6 \times 2704$ SHS $)$. Only two of the tests reported by Goggins et al. (2006) were used in the verification since in other tests either failure was not reached or fracture occurred close to the weld, examination of which is outside the scope of this study.

Complete fracture of a specimen is a common definition of failure but is not always appropriate for signalling significant loss of resistance of a member. Once a crack occurs, typically in the corner region of a section, it grows quickly and the reduction in cross-sectional area weakens the specimen. Some specimens survived a number of additional cycles following corner opening by relying on a small fraction of the crosssection remaining intact; however, in practice, such a bracing member will no longer be capable of providing effective lateral stiffness to the frame. Therefore, in this study, the number of cycles to failure has been defined as the cycle when small cracks at the corner grow into an opening, which can often be indentified in a load-displacement hysteresis curve by a sudden drop in load. Hysteresis curves from selected FE simulations and corresponding tests on specimens of the three materials are shown in Figures 8-10. The comparison shows that the FE models are capable of simulating the hysteretic behaviour well for all three materials.

All models predict crack initiation at corner areas of the mid-span section where large localised plastic strain amplitudes are induced by local buckling. The same failure 
mode has been observed in experimental studies on hollow section members subjected to cyclic axial loading (Goggins et al., 2006, Nip et al., 2010b) as well as during testing of full-scale braced frames under seismic loading (Yoo, et al., 2008). In the experiments, these cracks propagate and ultimately lead to the complete fracture at the mid-length section.

A comparison between the number of cycles to failure and predictions from the FE models is presented in Table 2. The agreement between the test and FE results is good with only a few exceptions which may be due to premature cracking in the weld regions, which was evident for 6 specimens (see Table 2). These cracks reduce the rotational stiffness at the ends of the specimens and increase their effective length, which lessens the rotation at the mid-length. The discrepancy between the results of Goggins et al. (2006) and the described numerical models may be due to the limited information on the material properties necessitating the assumption of several parameters. The discussions of the remainder of this paper focus on cold-formed carbon steel braces, which have been the most commonly used and tested in the past.

\subsection{Parametric studies}

The primary aim of the parametric studies was to investigate the influence of global and local slendernesses on the structural behaviour of hollow section bracing members, examining, in particular, the number of cycles to failure. The global slenderness is defined as $\bar{\lambda}=\sqrt{\mathrm{f}_{\mathrm{y}} \mathrm{A} / \mathrm{N}_{\mathrm{cr}}}$ where $\mathrm{f}_{\mathrm{y}}$ is the yield strength, $\mathrm{A}$ is the crosssectional area, and $\mathrm{N}_{\mathrm{cr}}$ is the elastic critical buckling load. The local slenderness is 
defined $a s / t \varepsilon$ where $b$ is the flat width of the wider face of the section, $t$ is the thickness of the section and $\varepsilon=\sqrt{235 / \mathrm{f}_{\mathrm{y}}}$.

In order to study the effects of changing global and local slendernesses, a series of $40 \mathrm{~mm} \times 40 \mathrm{~mm}$ SHS braces with various thicknesses of the sections and the lengths of the members were modelled. All models in the series satisfy the local and global slenderness requirements in EN 1998-1 (2004) for ductile behaviour. Although a series of members with various section sizes may also result in members with different global slenderness, a sensitivity study showed that there was no clear trend of the influence of global slenderness in such a series, and therefore the results were not included in this paper.

The braces of the chosen series of members were subjected to the loading history described in Section 2.4. The predicted numbers of cycles to the initiation of global and local buckling, and to eventual fatigue fracture, based on the four strain measures described in Section 2.6, are given in Table 3, alongside displacement ductility of the members, $\mu_{\Delta}$. As explained in Section 2.6, the case of SP-peak, using the peak strains from the most critical location and assuming maximum values through the thickness, gave the lowest fracture lives. In contrast, the case of SPN-avg gave the lowest strain amplitudes and predicted the longest fracture lives. For the remainder of the study, fracture lives were predicted on the basis of SP-avg due to the low sensitivity to mesh size and ability to reflect the influence of local bending.

\section{$5 \quad$ Analysis of results}




\subsection{Results of the current investigation}

In the parametric studies, both global and local slendernesses were varied. Their individual influences were isolated by analysing the results in groups of members with constant section thickness or member length. The numbers of cycles at which global buckling, local buckling and fracture occurred for members with constant section thicknesses but varying member length are shown in Figures 11-14. The same set of data was reorganised and plotted in Figures 15-18 to show the influence of local slenderness on the behaviour of the members.

As observed in experiments (Tremblay, 2002, Goggins et al., 2006, Nip et al. 2010b), the fatigue fracture of models of hollow section braces is shown to initiate at the corner areas, where material ductility is lower and high localised strains develop due to the redistribution of load following local buckling (Figure 5). The resistance to local buckling depends on the elastic local buckling stress of a plate element, which decreases as its width-to-thickness ratio increases. As a result, a section with high local slenderness is more prone to local buckling. The influence of local slenderness is clearly shown by the trends of number of cycles to local buckling and fracture in Figures 16-19 and has been observed in experiments Han et al. (2007).

It has been reported in previous investigations that local buckling is more severe in braces with low global slenderness, even if local slenderness is kept low (Tremblay, 2002). This is caused by the higher compressive strains induced in the plastic hinges that form in braces with lower global slenderness. This is generally supported by the 
results from the current study as illustrated in Figures 11-14 in which it is shown that the braces with lower global slenderness have lower numbers of cycles to the initiation of local buckling, even though the local slenderness is kept constant. This implies that less slender braces experience higher compressive strains which induce earlier local buckling. These observations suggest that global slenderness influences behavioural aspects related to the local buckling of the braces, such as the amplitude of compressive strain on the braces before local buckling and the severity of local buckling once it has initiated. These aspects are discussed further below.

\subsection{Comparison with previous investigations}

Figures 19 and 20 summarise the relationship between slenderness and the number of cycles to failure for all models in the current investigation. Although the current study shows that both global slenderness and local slenderness have influence on the fracture life of a member, the effects of these slenderness parameters have not always been observed in experiments, leading to mixed conclusions on the relative importance of these geometric parameters. To discuss this aspect of behaviour, observations from previous studies are compared with the results from the current numerical and associated experimental investigation (Nip et al., 2010b).

It was indicated in a previous comprehensive survey of cyclic tests on braces (Tremblay, 2002) that fracture of bracing members depended strongly on global slenderness and, to a lesser extent, on local slenderness, and a linear regression analysis was performed to show that ductility of members increased with global slenderness. Importantly, however, it was pointed out that in the experimental 
database examined (Tremblay, 2002), braces with low global slenderness usually had high local slenderness, i.e. large sections with thin walls, suggesting that global slenderness may not be the sole factor affecting the fracture lives. This indicates that the experimental results may well be interpreted in a different manner. To illustrate this, Figures 21-22 depict the global and local slendernesses of all SHS and RHS members from previous tests available (Archambault et al., 1995, Black et al., 1980, Goggins et al., 2006, Gugerli, 1982, Han et al., 2007, Lee and Goel, 1987, Liu, 1987, Shaback, 2001, Walpole, 1996). The figures demonstrate this inter-relationship for most data, as seven out of the nine programmes exhibit this trend in specimen selection (Figure 21). This suggests that additional tests on slender braces with thin walls, as well as stockier braces with thick walls, are needed to ascertain the influence of local and global slenderness in isolation.

In the two experimental programmes in which local and global slenderness were isolated to some extent (Walpole, 1996, Han et al., 2007) (Figure 22), the importance of global slenderness and local slenderness respectively can be observed. Walpole (1996) indicated that, in the absence of the influence of local slenderness, the number of cycles to failure dropped from 8 to 7 only as the global slenderness decreased from 1.8 to 0.4 . Han et al. (2007) selected specimens with a very large range of local slenderness and limited variety in global slenderness to show that the number of cycles to failure indeed depended significantly on the local slenderness.

Nevertheless, the co-existing influence of the global slenderness and local slenderness has been given attention by some researchers (Shaback and Brown, 2003, Goggins et al., 2006). In the test programme conducted by Goggins et al. (2006), although the 
specimens with high global slenderness had low local slenderness, and vice versa (Figure 21), the influence of the global slenderness and local slenderness was observed. Two linear regression analyses were performed to establish the relationships between the number of cycles to failure and these two slenderness parameters respectively:

$$
\begin{aligned}
& \mu_{\Delta}=26.2 \bar{\lambda}-0.7 \\
& \mu_{\Delta}=29.1-1.07(\mathrm{~b} / \mathrm{t})
\end{aligned}
$$

where $\mu_{\Delta}$ is the displacement ductility (defined as the peak displacement divided by the yield displacement), $\bar{\lambda}$ is the non-dimensional global slenderness and $b / t$ is the local slenderness.

Similarly, based on the test data of Shaback (2001), Shaback and Brown (2003) concluded that both the global slenderness and local slenderness were influential for different aspects of the hysteretic response of braces. Empirical formulae were proposed to predict the fracture life of SHS braces, as represented by a weighted axial deformation $\left(\Delta_{\mathrm{f}}\right)$ at failure. They are given as:

$$
\begin{array}{ll}
\Delta_{\mathrm{f}}=\mathrm{C}_{\mathrm{s}} \frac{\left(350 / \mathrm{f}_{\mathrm{y}}\right)^{-3.5}}{[(\mathrm{~b}-2 \mathrm{t}) / \mathrm{t}]^{1.2}}\left(\frac{4(\mathrm{~b} / \mathrm{d})-0.5}{5}\right)^{0.55}(70)^{2} & \text { for } \frac{\mathrm{KL}}{\mathrm{r}}<70 \\
\Delta_{\mathrm{f}}=\mathrm{C}_{\mathrm{s}} \frac{\left(350 / \mathrm{f}_{\mathrm{y}}\right)^{-3.5}}{[(\mathrm{~b}-2 \mathrm{t}) / \mathrm{t}]^{1.2}}\left(\frac{4(\mathrm{~b} / \mathrm{d})-0.5}{5}\right)^{0.55}\left(\frac{\mathrm{KL}}{\mathrm{r}}\right)^{2} & \text { for } \frac{\mathrm{KL}}{\mathrm{r}}>70
\end{array}
$$

where $C_{s}$ is an empirical constant taken as $0.065, \mathrm{~K}$ is the effective length factor, $\mathrm{b}$ is the longer face of the cross-section, $d$ is the shorter face of the cross-section, $t$ is the thickness of cross-section, $r$ is the radius of gyration and $f_{y}$ is the material yield strength in $\mathrm{N} / \mathrm{mm}^{2}$. However, this cumulative measure is sensitive to the shape of the 
hysteretic loops, which has a large variability when different loading histories are applied. Tremblay et al. (2003) proposed an expression for rotation at fracture, $\theta_{\mathrm{f}}$, in terms of both slenderness parameters:

$$
\theta_{\mathrm{f}}=0.091\left(\frac{\mathrm{b}}{\mathrm{t}} \frac{\mathrm{d}}{\mathrm{t}}\right)^{-0.1}\left(\frac{\mathrm{KL}}{\mathrm{r}}\right)^{0.3}
$$

where $b / t$ is the section width-to-thickness ratio, $d / t$ is the section depth-to-thickness ratio, $\mathrm{KL}$ is the effective length and $\mathrm{r}$ is the radius of gyration. Specimens with a range of $\mathrm{b} / \mathrm{t}(8.0-32.0), \mathrm{d} / \mathrm{t}(13.4-32.0)$ and $\mathrm{KL} / \mathrm{r}(34.6-92.0)$ ratios were used to calibrate Equation 10. This expression, although providing better predictions than Equations 6-9, has been found to underestimate the rotation at fracture implied from recent experiments (Nip et al., 2010b), which included tested specimens with a comparable range of $\mathrm{b} / \mathrm{t}(10.7-21.6), \mathrm{d} / \mathrm{t}(10.8-21.9)$ and $\mathrm{KL} / \mathrm{r}(21.5-81.6)$ ratios. Even if those specimens with dimensions out of the applicability of Equation 10 are ignored, the general underestimation of the rotation at fracture still exists.

In order to address the co-existing influence of global slenderness and local slenderness observed in the current and other studies, an expression for predicting displacement ductility is proposed. This expression is calibrated against the results of 5 test series (Walpole, 1996, Goggins et al, 2006, Nip et al., 2010b) and 15 FE models (Nip et al., 2010b) on cold-formed carbon steel hollow section members with $\bar{\lambda}$ from 0.39 to 1.78 and $b / t \varepsilon$ from 8.2 to 29.3 :

$$
\mu_{\Delta}=6.45+2.28 \bar{\lambda}-0.11(\mathrm{~b} / \mathrm{t} \varepsilon)-0.06(\bar{\lambda})(\mathrm{b} / \mathrm{t} \varepsilon)
$$

The above relationship is expressed in terms of displacement ductility rather than rotation at fracture as this can be more readily related to ductility demands adopted in design procedures. A multiple regression analysis has been carried out on Equation 11. 
An F-value of 2.6, greater than the critical F-value of 2.4 at the $90 \%$ confidence level, indicates that the relationship is useful for predicting displacement ductility. The parameters of the equation individually make significant contribution to the prediction as shown by their t-values at 2.04, 0.68, 0.69 and 0.36 , respectively, which are greater than the critical t-value of 0.26 at the $60 \%$ confidence level. The ratio between the predicted ductility from Equation 11 and measurements from the experimental and FE models has a mean of 1.10 and coefficient of variation of 0.30 , which are deemed satisfactory considering the highly variable nature of fatigue fracture (Figure 23). The coefficients of this expression can also be changed to fit the data of specimens of other materials, as reported by Nip et al. (2010b), who also showed that the fitness of Equation 11 is better than other available relationships (i.e. Equations 6-10). Although a number of factors have been identified as influential on the fracture behaviour of bracing members, the proposed predictive equation (Equation 11) provides a simple means of determining displacement ductility on the basis of global and local slenderness.

\section{Conclusions}

Diagonal bracing members experience repeated cycles of yielding in tension and buckling in compression when a braced frame is subjected to severe seismic loading. The hysteretic response of the bracing members has been studied experimentally in previous investigations but little attention has been given to the ultimate behaviour and failure conditions. Despite the availability of several proposed rules for predicting the ductility capacity of braces, there are significant uncertainties in these predictions. 
Therefore, a numerical study has been carried out to clarify these issues. In the study, FE models were developed to investigate the cyclic response of SHS braces and a strain-based damage assessment method was adopted to predict the fracture lives of the members. This method was verified against experimental results.

A parametric study was conducted to investigate the influence of global and local slendernesses on the number of cycles to failure. Local buckling was found to be crucial to the promotion of fracture since it induces high localised strains at the corner areas of the sections, which, in the case of cold-formed braces, also have lower ductility. Braces with low local slenderness have high resistance to local buckling and hence delay fracture. Global slenderness of the braces, through various influencing factors, affects the compressive strains before the occurrence of local buckling and the severity of the buckling once it has initiated. Both global and local slendernesses therefore have a direct influence on the number of cycles to failure of the braces.

Observations from the current study have highlighted some inconsistencies with conclusions found in the literature, where fracture life has been deemed to increase with global slenderness but was often found not to vary significantly with local slenderness. The apparent contradiction with the findings of the current study is due to the difficulty in isolating the effects of global and local slendernesses in some studies. An alternative selection of specimens to confine changes to only one variable at a time in other programmes (Walpole, 1996, Han et al., 2007) gives a clearer view on the effects of each of these factors. A relationship which addresses the co-existing influence of global slenderness and local slenderness on fatigue fracture and displacement ductility has been proposed in this study. This relationship provides 
satisfactory prediction for cold-formed square and rectangular hollow section members with $\bar{\lambda}$ ranging from 0.39 to 1.78 and $b / t \varepsilon$ ranging from 8.2 to 29.3 .

\section{References}

ABAQUS. Analysis User's Manual I-V. Version 6.7. ABAQUS, Inc., Dassault Systèmes, USA, 2007

Archambault M.H., Tremblay R. and Filiatrault A. Étude du comportement séismique des contreventements ductiles en $X$ avec profiles tubulaires en acier. Department of Civil Engineering, École Polytechnique, Montréal, Canada, 1995, Rapport no. EPM/GCS-1995-09.

Ashraf M., Gardner L. and Nethercot D. A. (2005). Strength enhancement of the corner regions of stainless steel cross-sections. Journal of Constructional Steel Research 61, No. 1, 37-52.

Black R.G., Wenger W.A.B. and Popov, E.P. Inelastic buckling of steel struts under cyclic load reversals. Earthquake Engineering Research Center, University of California, USA, 1980, Report no. UCB/EERC-80/40.

CEN. Design provisions for earthquake resistance of structures, Part 1: General rules, seismic actions and rules for buildings. CEN, Brussels, 2004, EN 1998-1.

Chan T.M. and Gardner L. (2009). Flexural buckling of elliptical hollow section columns. Journal of Structural Engineering, ASCE 135, No. 5, 546-557.

Coffin Jr. L.F. (1954). A study of the effects of cyclic thermal stresses on a ductile metal. Transactions of ASME 76, No. 6, 931-50. 
Cruise R.B. and Gardner L. (2008). Strength enhancements induced during cold forming of stainless steel sections. Journal of Constructional Steel Research 64, No. $11,1310-1316$.

Dawson R.G. and Walker A.C. (1972). Post-buckling of geometrically imperfect plates. Journal of Structural Engineering, ASCE 98, No. 1, 75-94.

ECCS. Recommended testing procedure for assessing the behaviour of structural steel elements under cyclic loads. ECCS, Brussels, 1986.

Elchalakani M., Zhao X.L. and Grzebieta R. (2003). Tests of cold-formed circular tubular braces under cyclic axial loading. Journal of Structural Engineering, ASCE 129, No. 4, 507-514.

Elghazouli A.Y. (2003). Seismic design procedures for concentrically braced frames. Proceedings of the Institution of Civil Engineers - Structures and Buildings 156, No. SB4, 381-394.

Ellobody E. and Young B. (2005). Structural performance of cold-formed high strength stainless steel columns. Journal of Constructional Steel Research 61, No. $12,1631-1649$.

Fell, B.V., Kanvinde, A.M., Deierlein, G.G. and Myers, A.T. (2009). Experimental investigation of inelastic cyclic buckling and fracture of steel braces. Journal of Structural Engineering, ASCE 135, No. 1, 19-32.

Gardner L. and Nethercot D.A. (2004). Numerical modeling of stainless steel structural components - a consistent approach. Journal of Structural Engineering, ASCE 130, No. 10, 1586-1601. 
Gardner L., Saari N. and Wang F. (2010). Comparative experimental study of hotrolled and cold-formed rectangular hollow sections. Thin-Walled Structures 48, No. 7, 495-507.

Goggins J.M., Broderick B.M., Elghazouli A.Y. and Lucas A.S. (2006). Behaviour of tubular steel members under cyclic axial loading. Journal of Constructional Steel Research 62, No. 1-2, 121-131.

Gugerli H. Inelastic cyclic behaviour of steel members. Ph.D. thesis. Department of Civil Engineering, University of Michigan. USA, 1982.

Han S.W., Kim W.T. and Foutch D.A. (2007). Seismic behavior of HSS bracing members according to width-thickness ratio under symmetric cyclic loading. Journal of Structural Engineering, ASCE 133, No. 2, 264-273.

Jain A.K., Goel S.C. and Hanson R.D. (1980). Hysteretic cycles of axially loaded steel members. Journal of the Structural Division, ASCE 106, No. 8, 1777-1795.

Kanvinde A.M., Fell B.V., Gomez I.R. and Roberts, M. (2008). Predicting fracture in structural fillet welds using traditional and micromechanical fracture models. Engineering Structures 30, No. 11, 3325-3335.

Karren K.W. (1967). Corner properties of cold-formed steel shapes. Journal of the Structural Division, ASCE 93, No. ST1, 401-432.

Lee S. and Goel S.C. Seismic behavior of hollow and concrete-filled square tubular bracing members. Department of Civil Engineering, University of Michigan, USA, 1987, Research report UMCE 87-11.

Liu Z. Investigation of concrete-filled steel tubes under cyclic bending and buckling. Ph.D. Thesis. Department of Civil Engineering, University of Michigan, Ann Arbor, Michigan, USA, 1987. 
Manson S.S. Behaviour of materials under conditions of thermal stress. National Lewis Flight Propulsion Laboratory, Cleveland, USA, 1954, Advisory Commission on Aeronautics: Report 1170.

Miner M.A. (1945). Cumulative damage in fatigue. Journal of Applied Mechanics 12 , No. 3, A159-A164.

Ng K.T. and Gardner L. (2007). Buckling of stainless steel columns and beams in fire. Engineering Structures 29, No. 7, 717-30.

Nip K.H., Gardner L., Davies C.M. and Elghazouli A.Y. (2010a). Extremely low cycle fatigue tests on structural carbon steel and stainless steel. Journal of Constructional Steel Research 66, No. 1, 96-110.

Nip K.H., Gardner L. and Elghazouli A.Y. (2010b) Cyclic testing and numerical modeling of carbon steel and stainless steel tubular bracing members. Engineering Structures. 32, No. 2, 424-441.

Popov E.P., Zayas V.A. and Mahin S.A. (1979). Cyclic inelastic buckling of thin tubular columns. Journal of the Structural Division, ASCE 105, No. 11, 2261-2277.

Rice J.R. (1968). Path independent integral and the approximate analysis of strain concentration for notches and cracks. Journal of Applied Mechanics 35, 379-386.

Shaback B. Behaviour of square HSS braces with end connections under reversed cyclic axial loading. Thesis submitted in partial fulfilment of the requirements for the degree of Master of Science. Department of Civil Engineering, University of Calgary, Canada, 2001.

Shaback B. and Brown T. (2003). Behaviour of square hollow structural steel braces with end connections under reversed cyclic axial loading. Canadian Journal of Civil Engineering 30, No. 4, 745-753. 
Tremblay R. (2002). Inelastic seismic response of steel bracing members. Journal of Constructional Steel Research 58, No. 5-8, 665-701.

Tremblay R., Archambault M.H., Filiatrault A. (2003). Seismic response of concentrically braced steel frames made with rectangular hollow bracing members. Journal of Structural Engineering, ASCE 129, No. 12, 1626-1636.

Walpole W.R. Behaviour of cold-formed steel RHS members under cyclic loading. Department of Civil Engineering, University of Canterbury, Christchurch, New Zealand, 1996, Research Report 96-4.

Yoo J., Lehman D.E. and Roeder C.W. (2008). Influence of connection design parameters on the seismic performance of braced frames. Journal of Constructional Steel Research 64, No. 6, 607-623. 


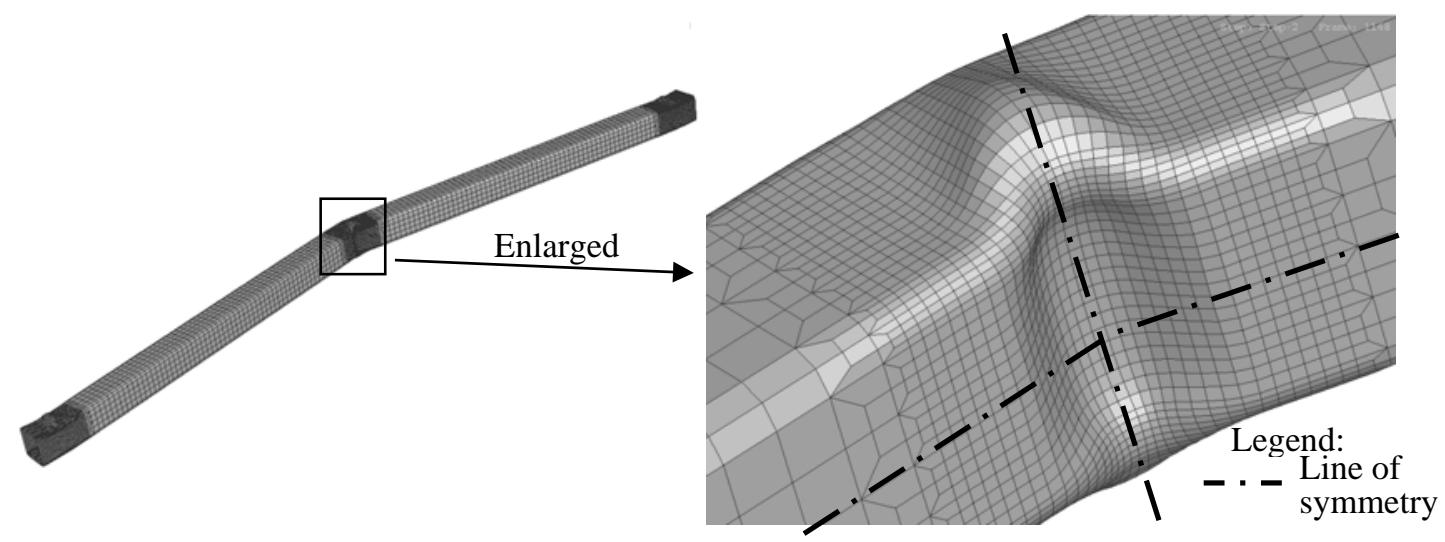

Figure 1. Refined mesh at the middle and ends of member (left), and the profile of local buckling and lines of symmetry (right)

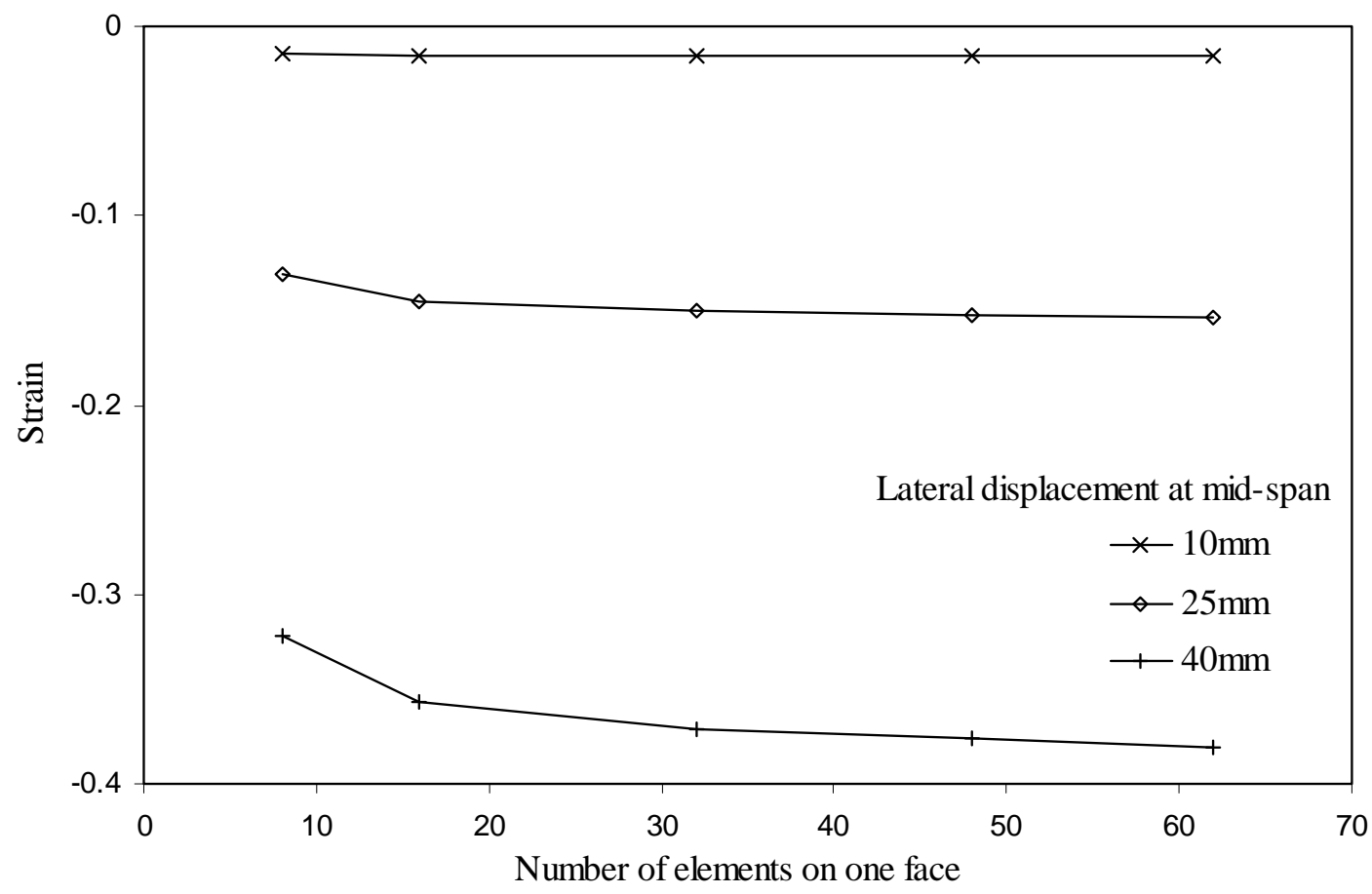

Figure 2. Output of average strains from different mesh sizes 


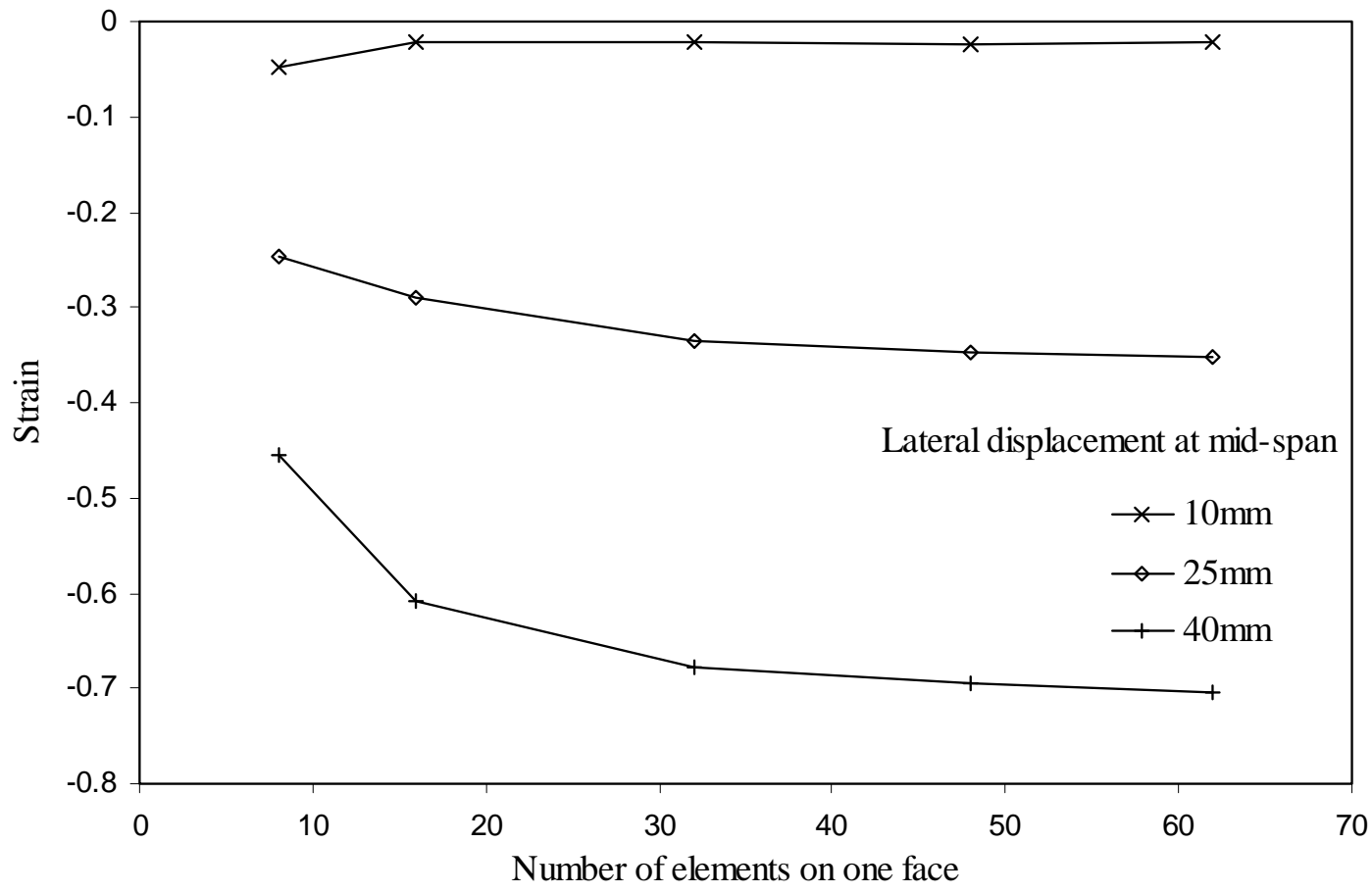

Figure 3. Output of peak element strains from different mesh sizes

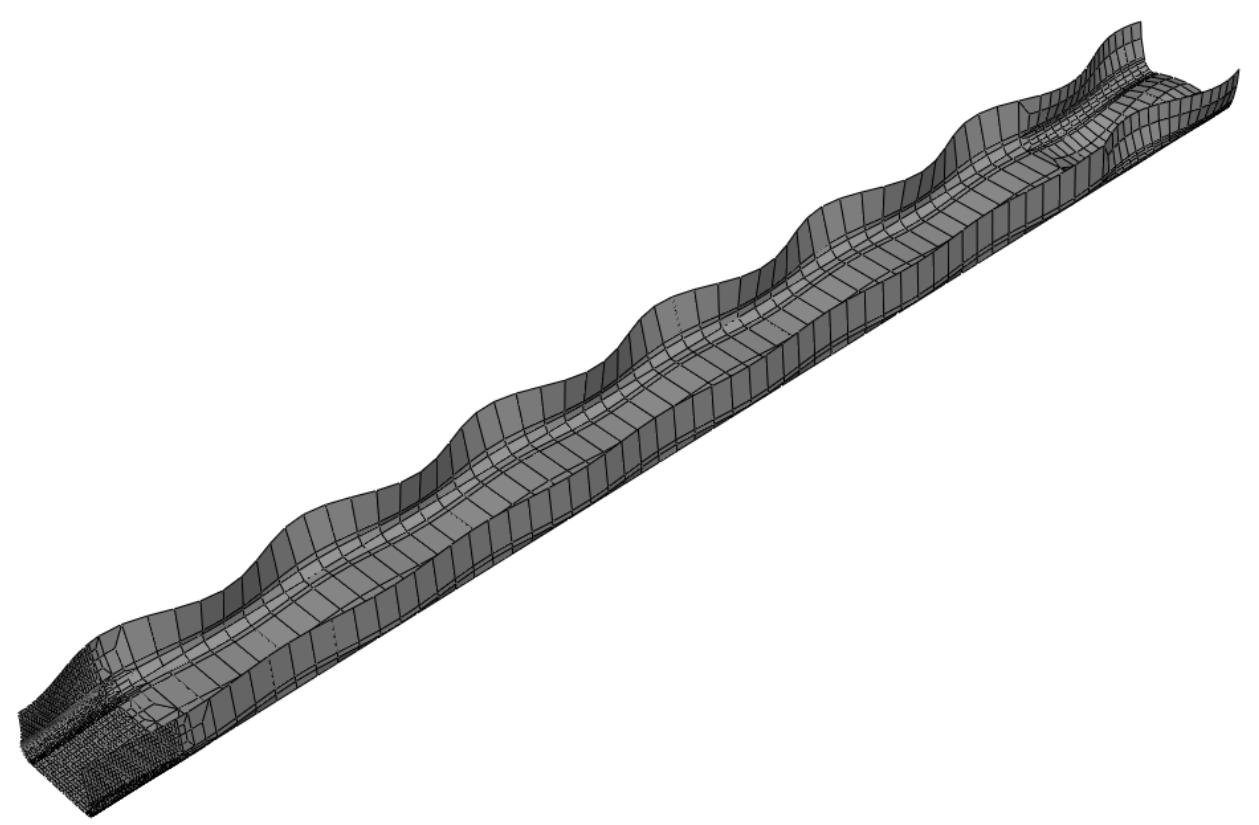

Figure 4. Exaggerated initial local imperfections (shown for a quarter member) 


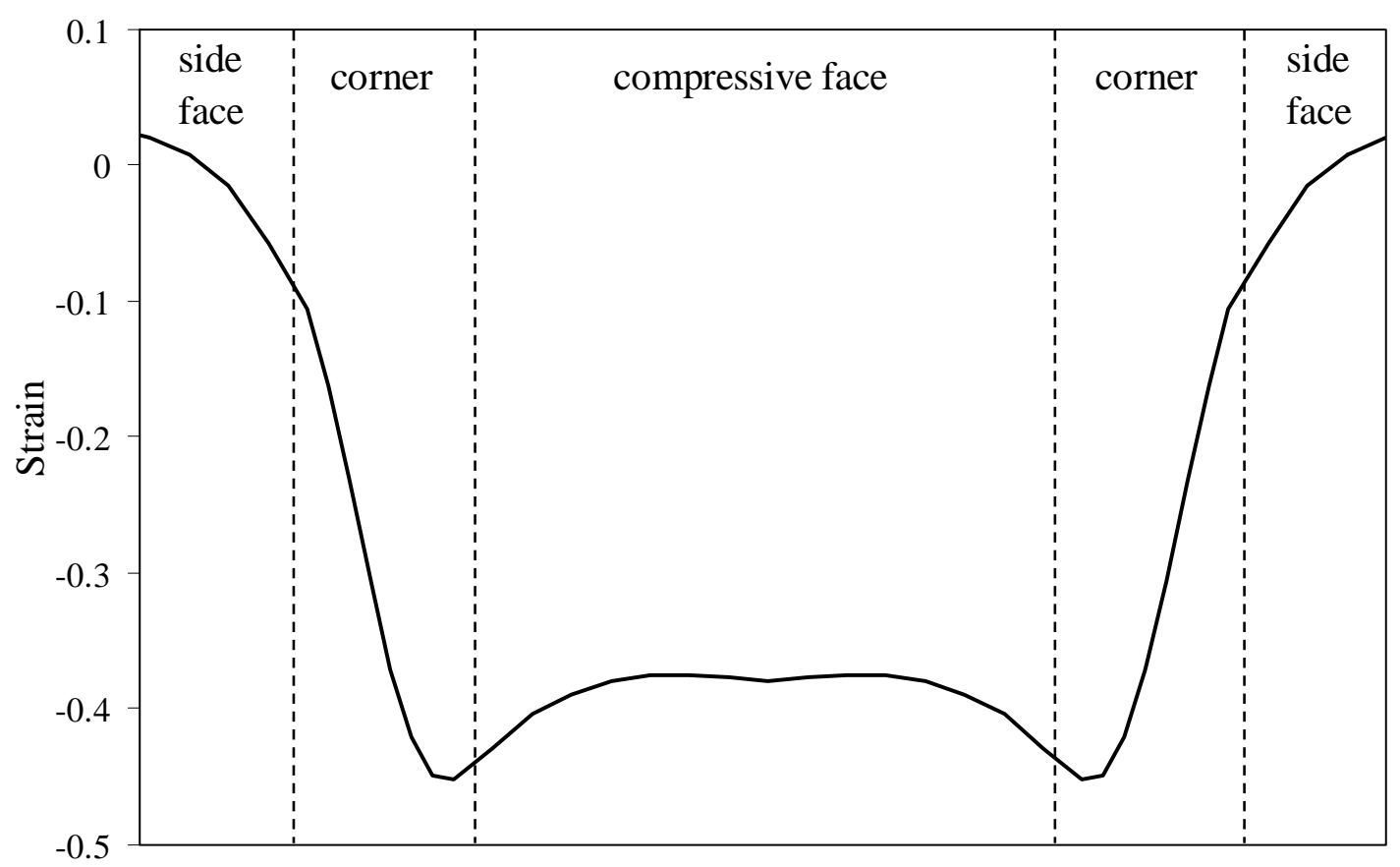

Elements around the cross-section

Figure 5. Strain distribution around the compressive face of the section at the region of local buckling

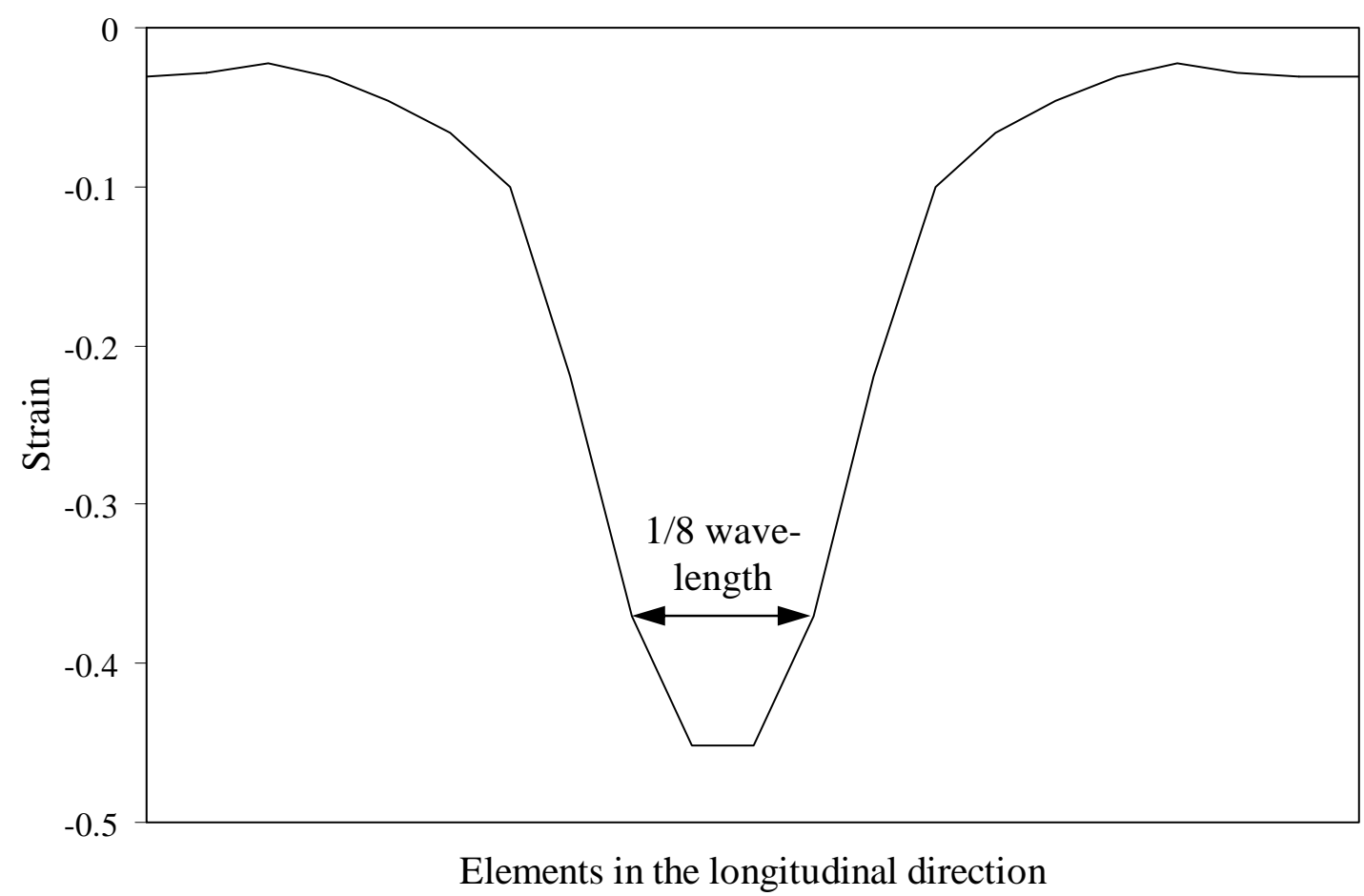

Figure 6. Strain distribution in the longitudinal direction of an element at the corner 


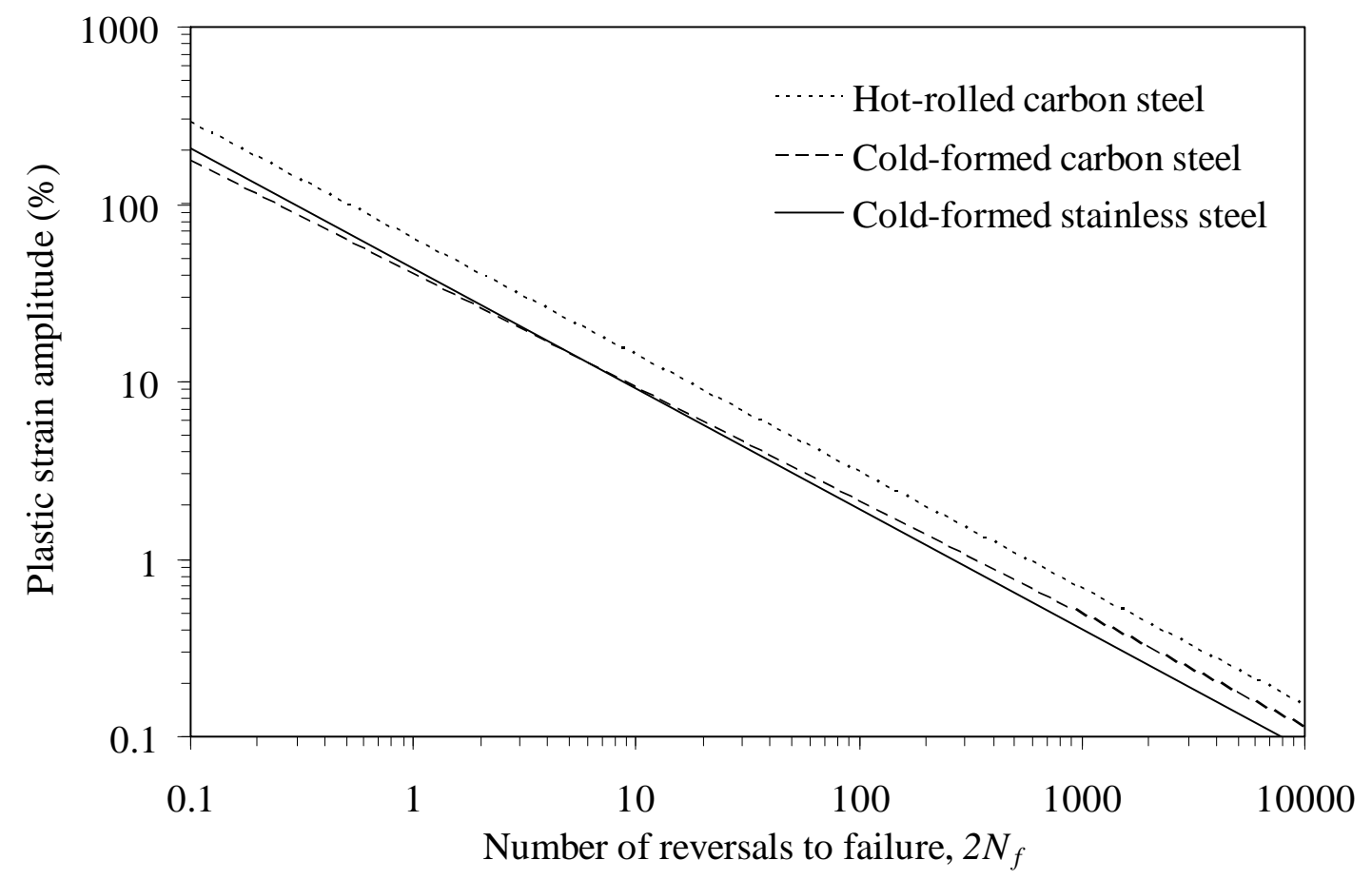

Figure 7. Plastic strain-life curves for hot-rolled carbon steel, cold-formed carbon steel and cold-formed stainless steel materials

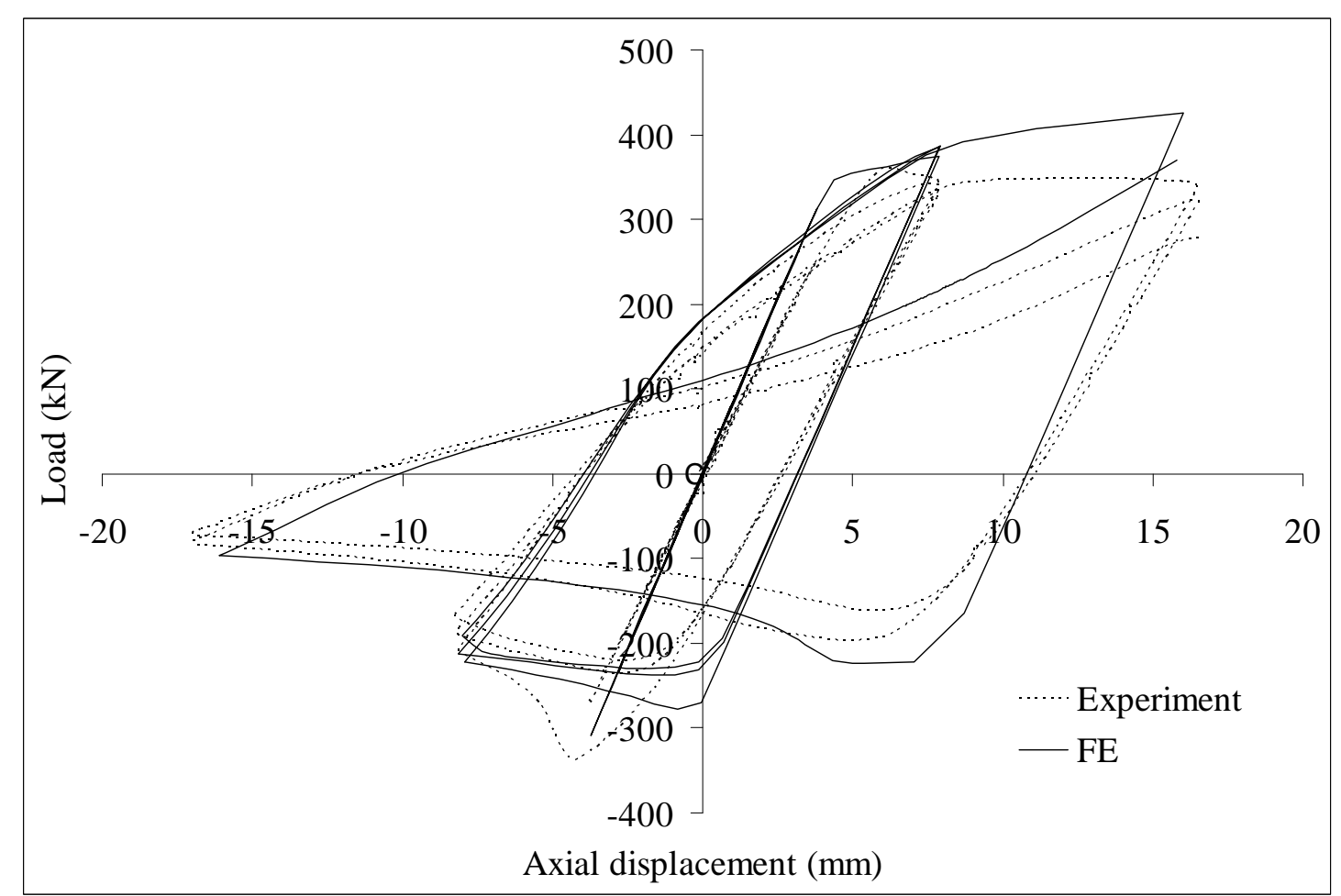

Figure 8. Comparison of hysteretic curves for specimen $60 \times 60 \times 3 \times 2050-C S-H R$ from FE simulation and experiment 


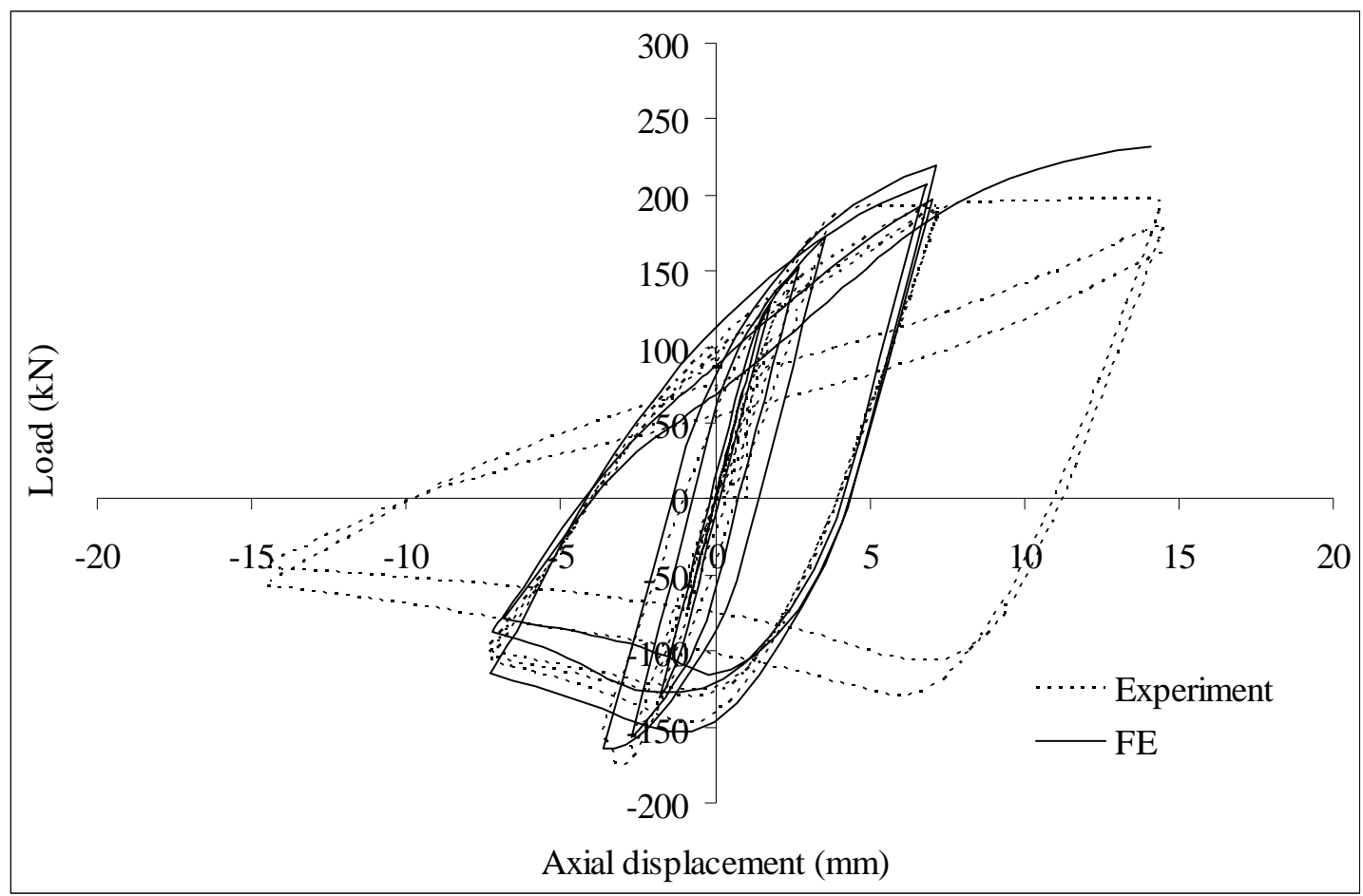

Figure 9. Comparison of hysteretic curves for specimen $40 \times 40 \times 3 \times 1250-C S-C F$ from FE simulation and experiment

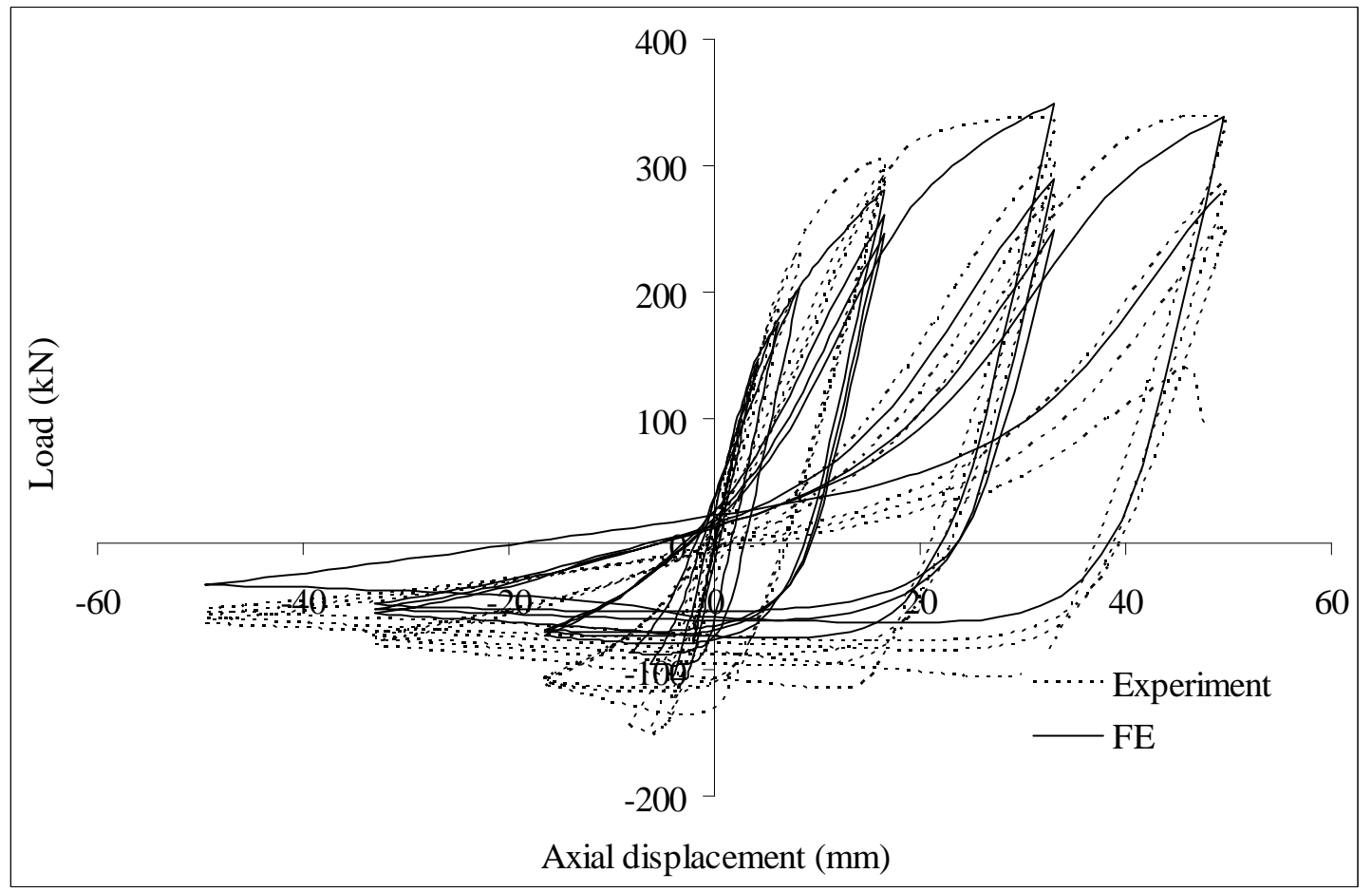

Figure 10. Comparison of hysteretic curves for specimen $50 \times 50 \times 3 \times 2850-$ SS-CF from FE simulation and experiment 


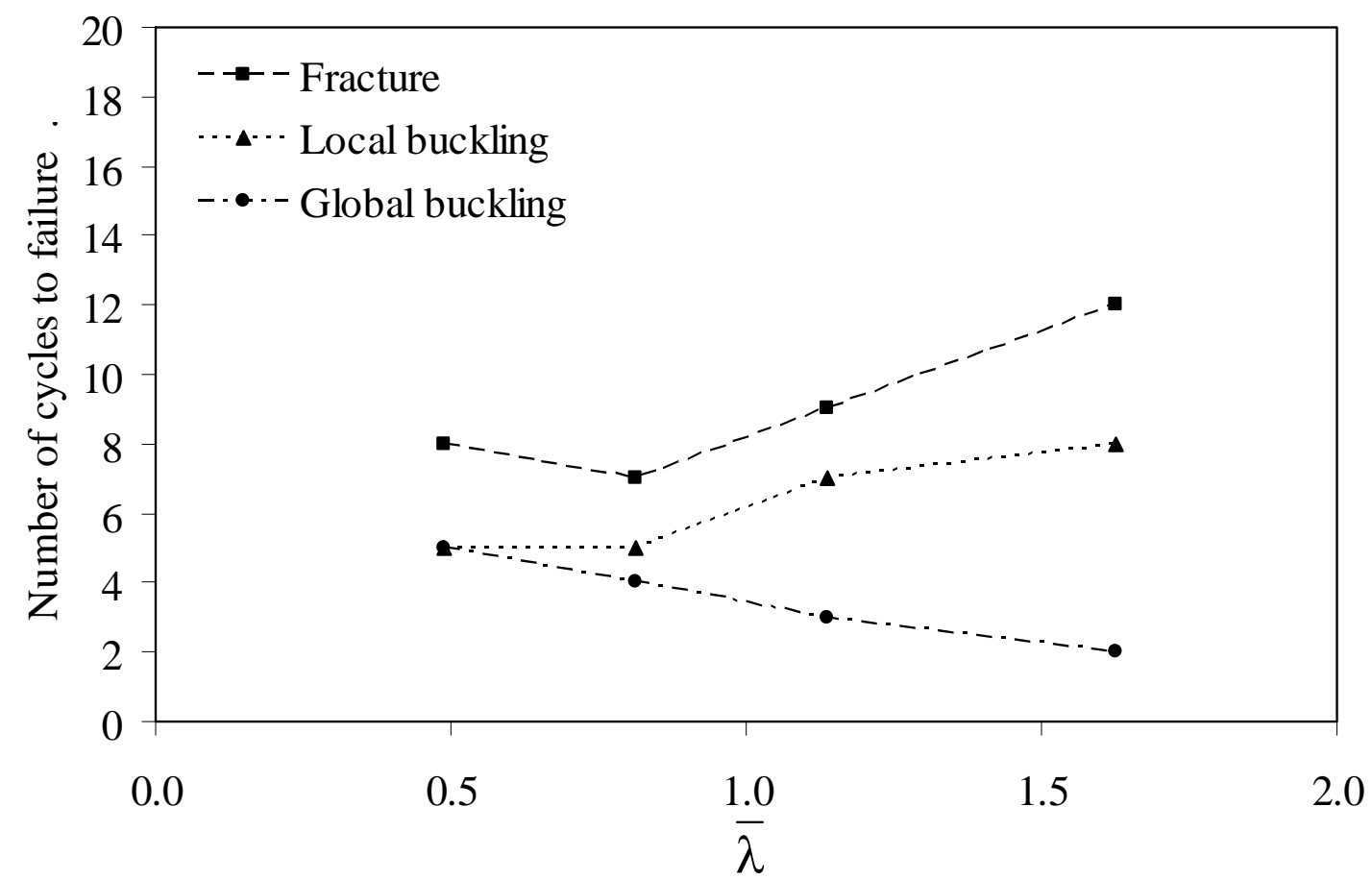

Figure 11. Global slenderness against numbers of cycles when global buckling, local buckling and fracture occurred for members with sections of $2.5 \mathrm{~mm}$ thick (b/t $\varepsilon=$ 27.4)

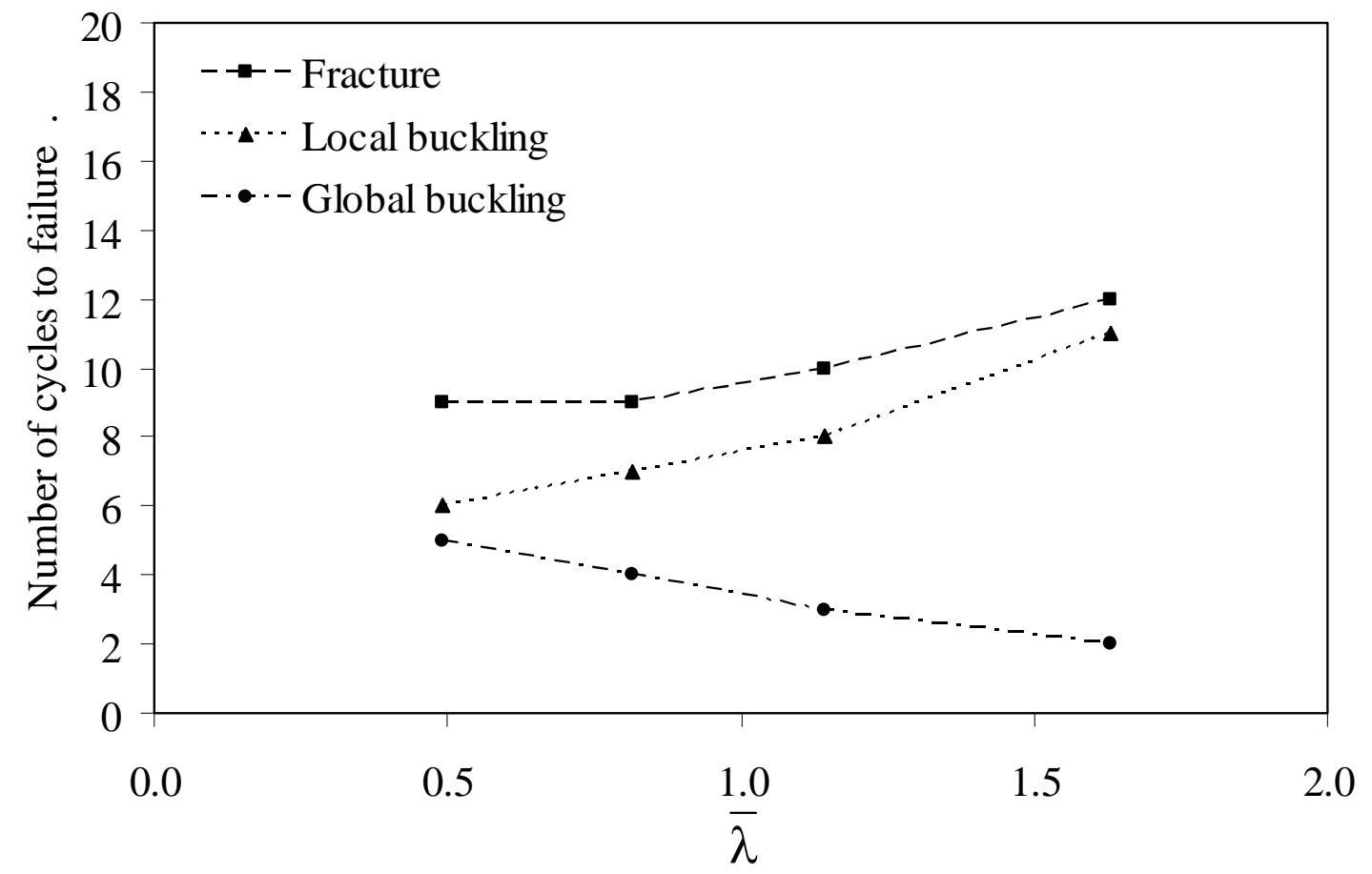

Figure 12. Global slenderness against numbers of cycles when global buckling, local buckling and fracture occurred for members with sections of $3.0 \mathrm{~mm}$ thick $(\mathrm{b} / \mathrm{t} \varepsilon=$ 21.9) 


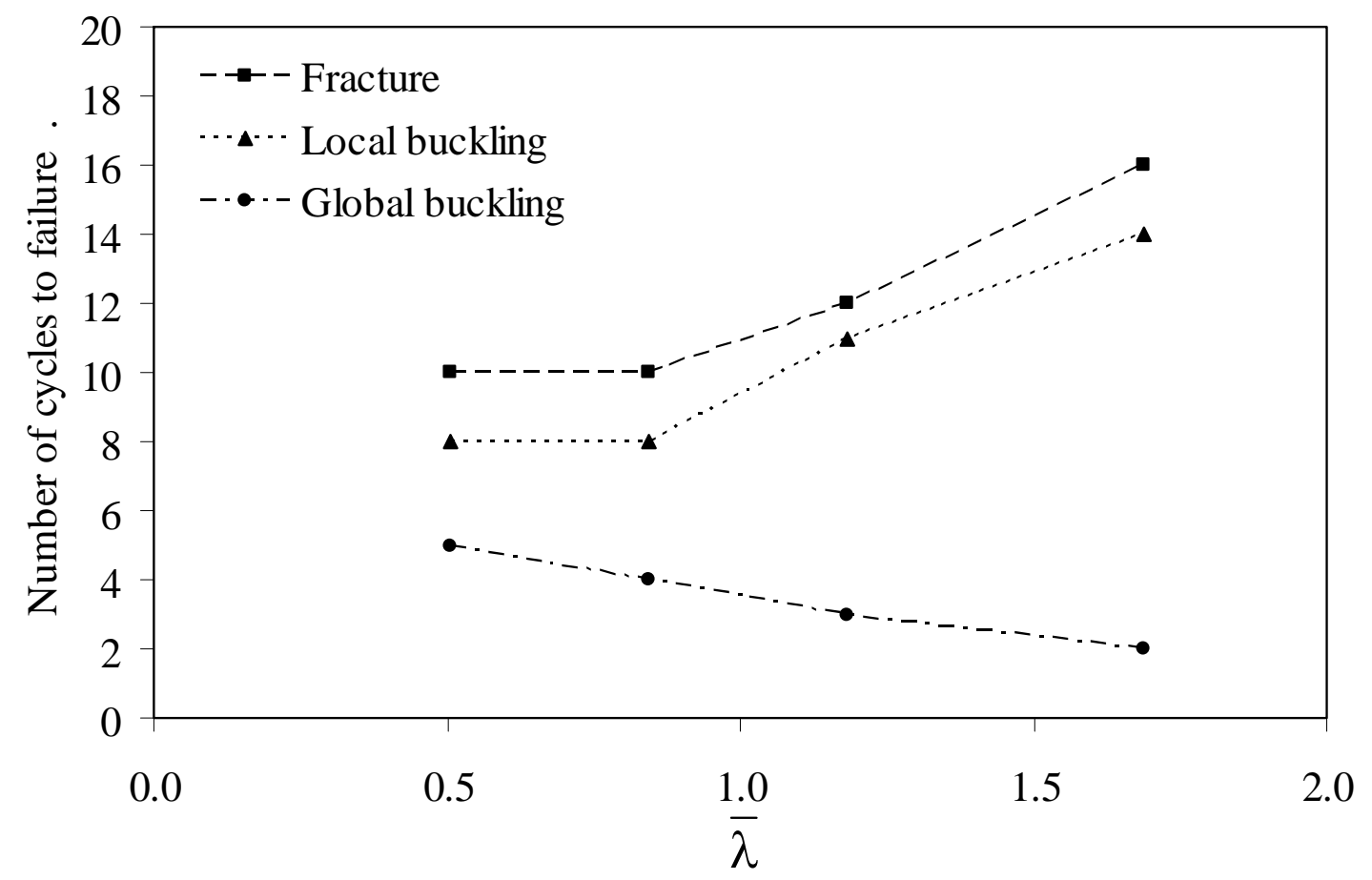

Figure 13. Global slenderness against numbers of cycles when global buckling, local buckling and fracture occurred for members with sections of $4.0 \mathrm{~mm}$ thick (b/t $\varepsilon=$ 15.1)

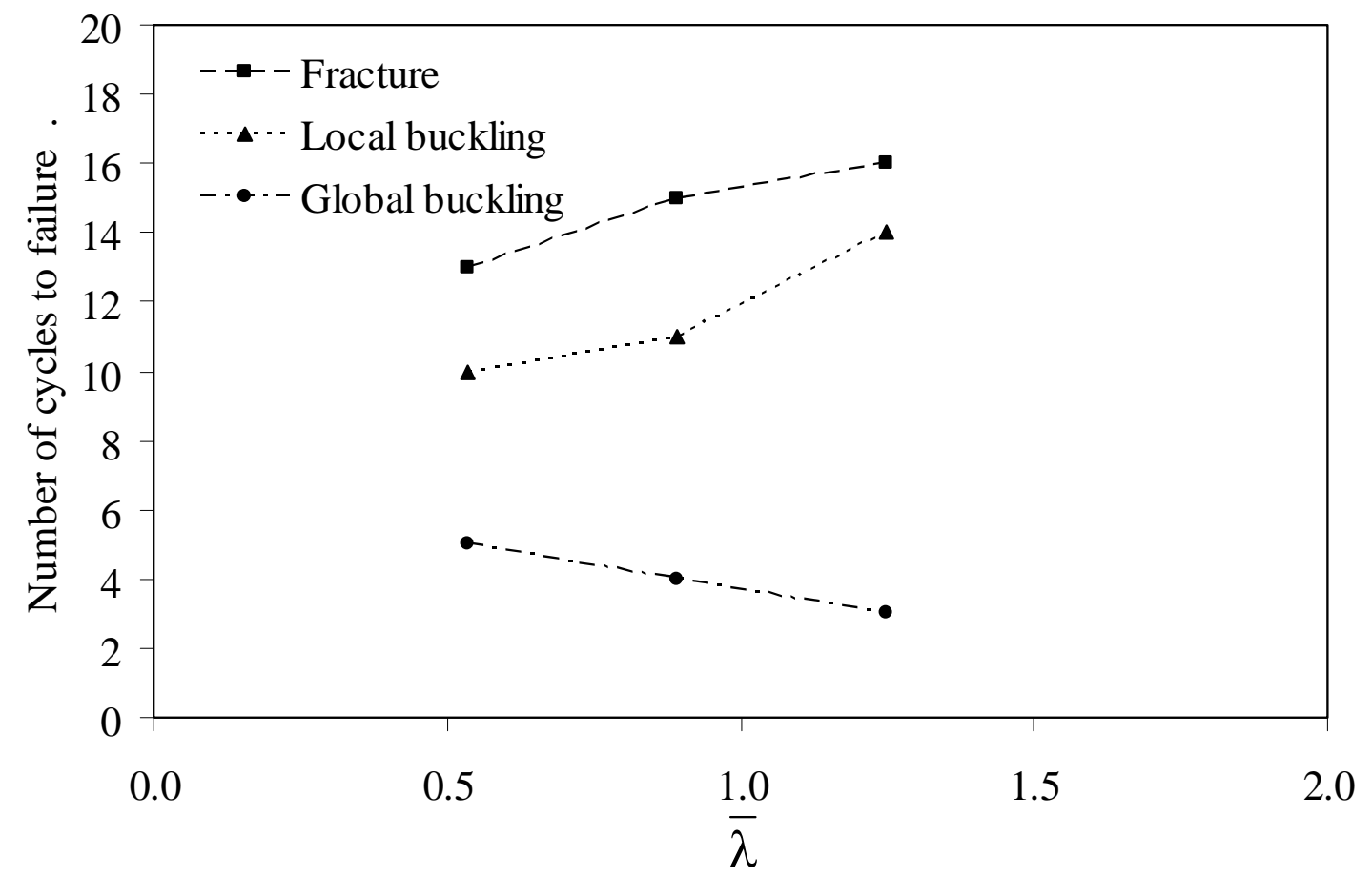

Figure 14. Global slenderness against numbers of cycles when global buckling, local buckling and fracture occurred for members with sections of $6.0 \mathrm{~mm}$ thick $(\mathrm{b} / \mathrm{t} \varepsilon=8.2$ ) 


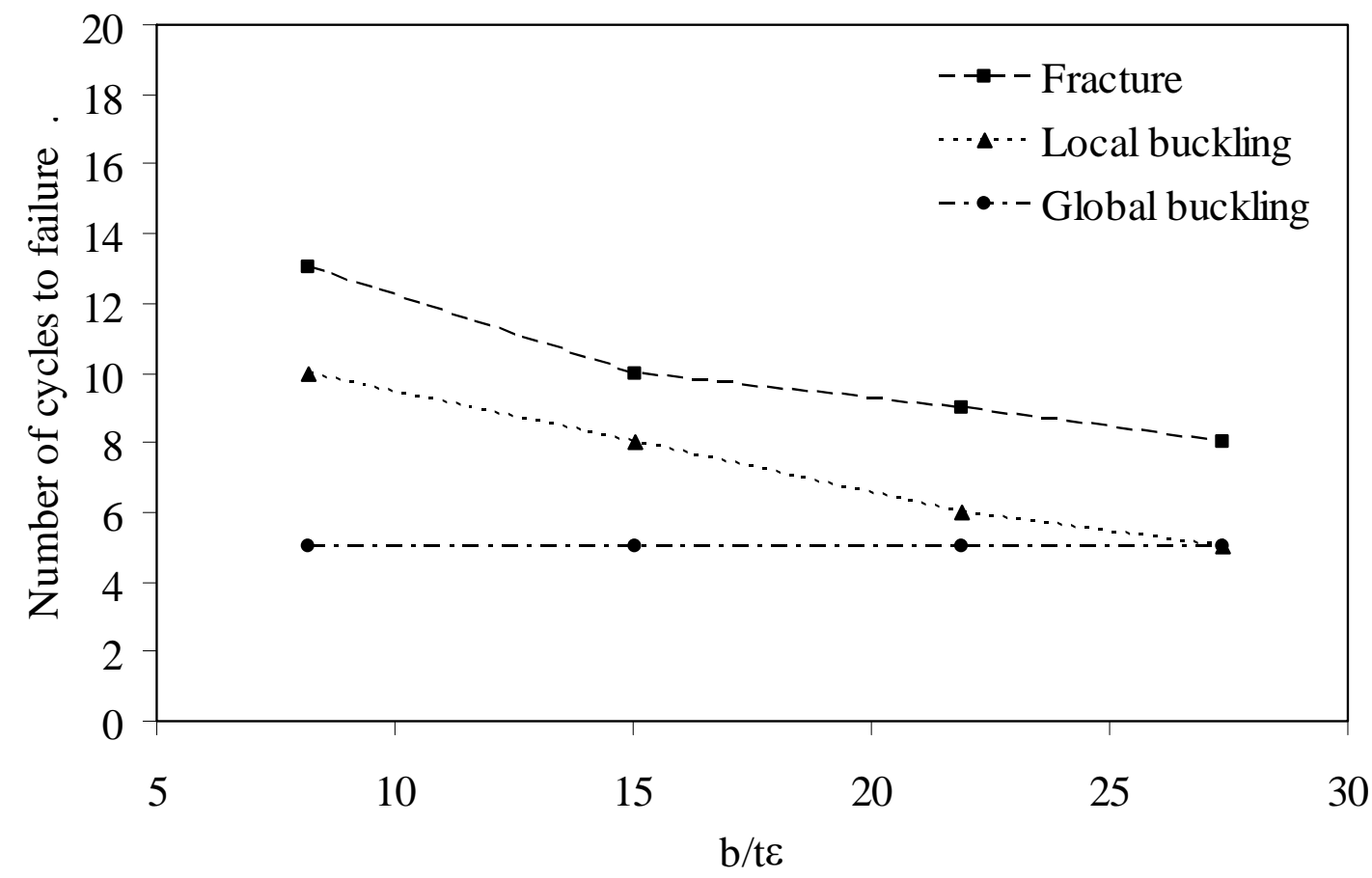

Figure 15. Local slenderness against numbers of cycles when global buckling, local buckling and fracture occurred for $1500 \mathrm{~mm}$ long members

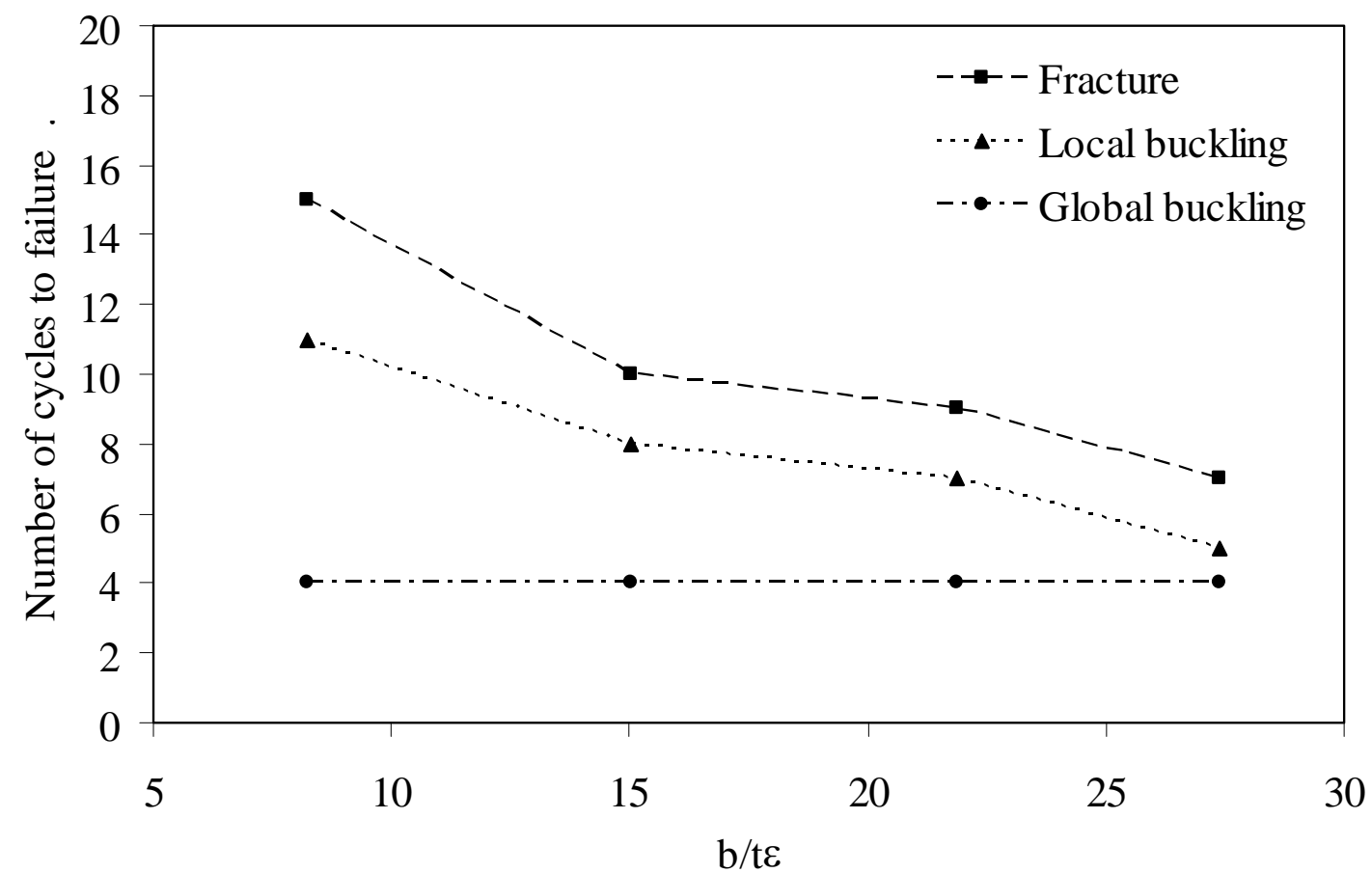

Figure 16. Local slenderness against numbers of cycles when global buckling, local buckling and fracture occurred for $2500 \mathrm{~mm}$ long members 


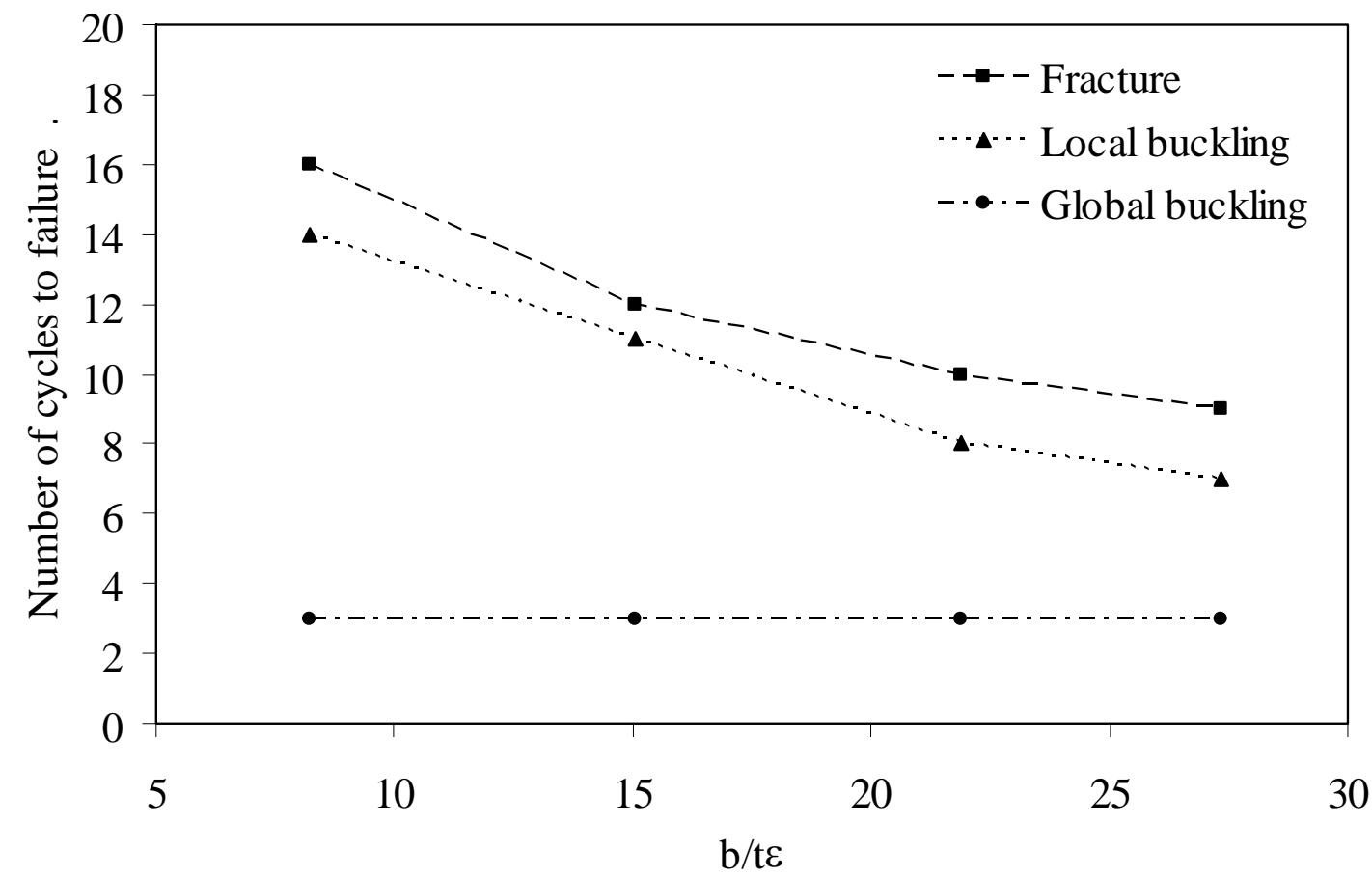

Figure 17. Local slenderness against numbers of cycles when global buckling, local buckling and fracture occurred for $3500 \mathrm{~mm}$ long members

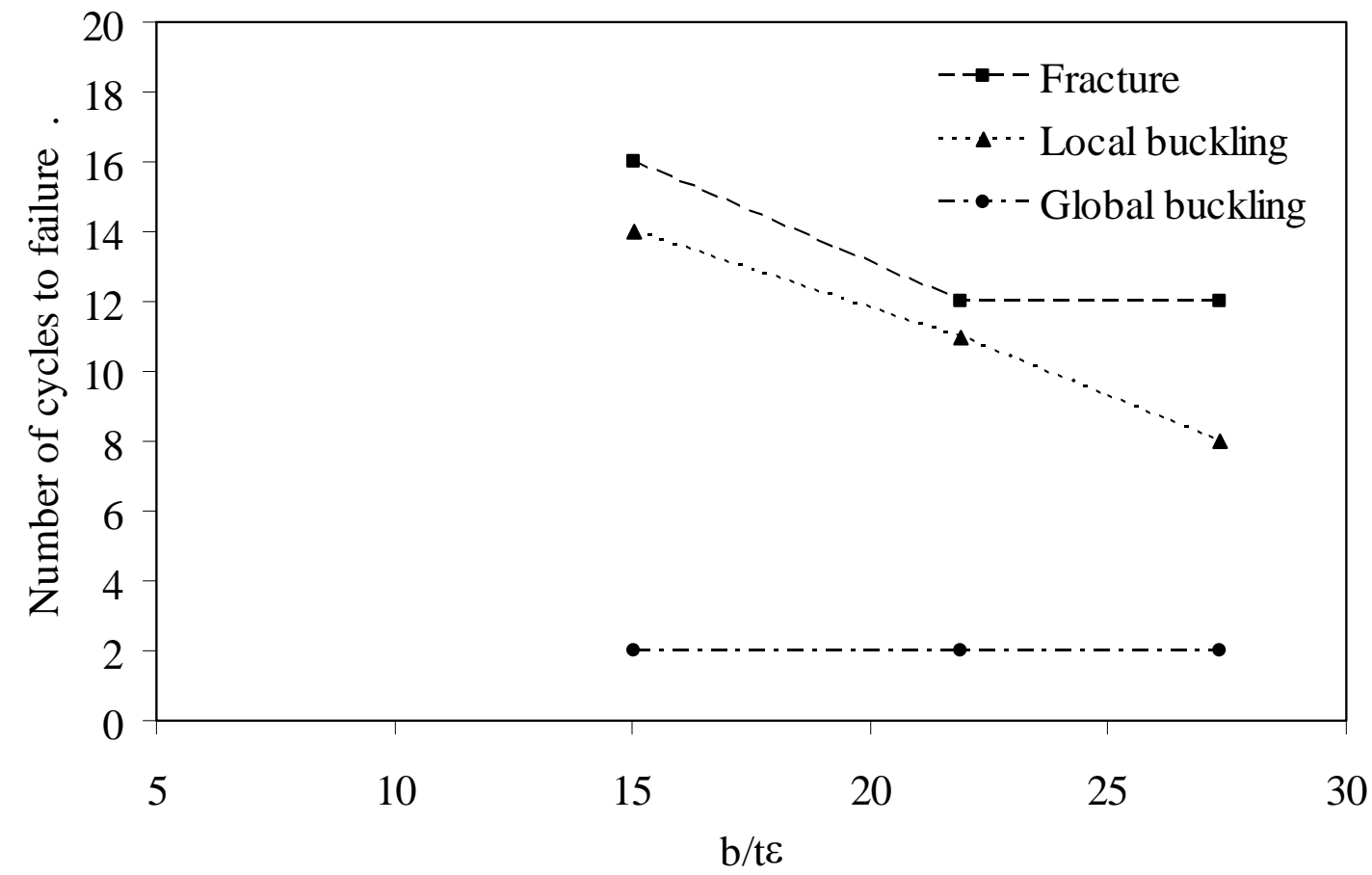

Figure 18. Local slenderness against numbers of cycles when global buckling, local buckling and fracture occurred for $5000 \mathrm{~mm}$ long members 


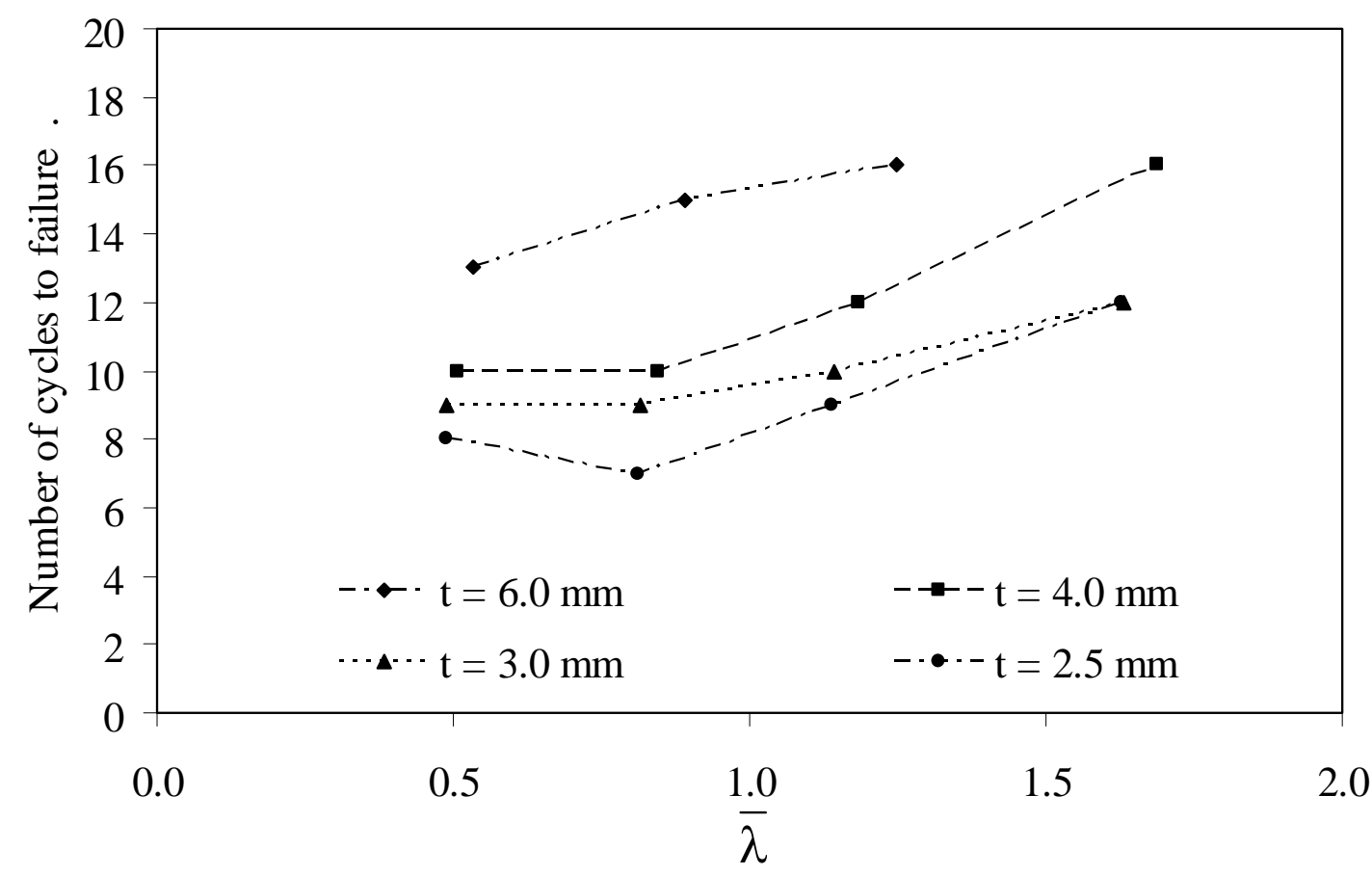

Figure 19. Relationship between global slenderness and number of cycles to failure of all specimens in the current parametric studies

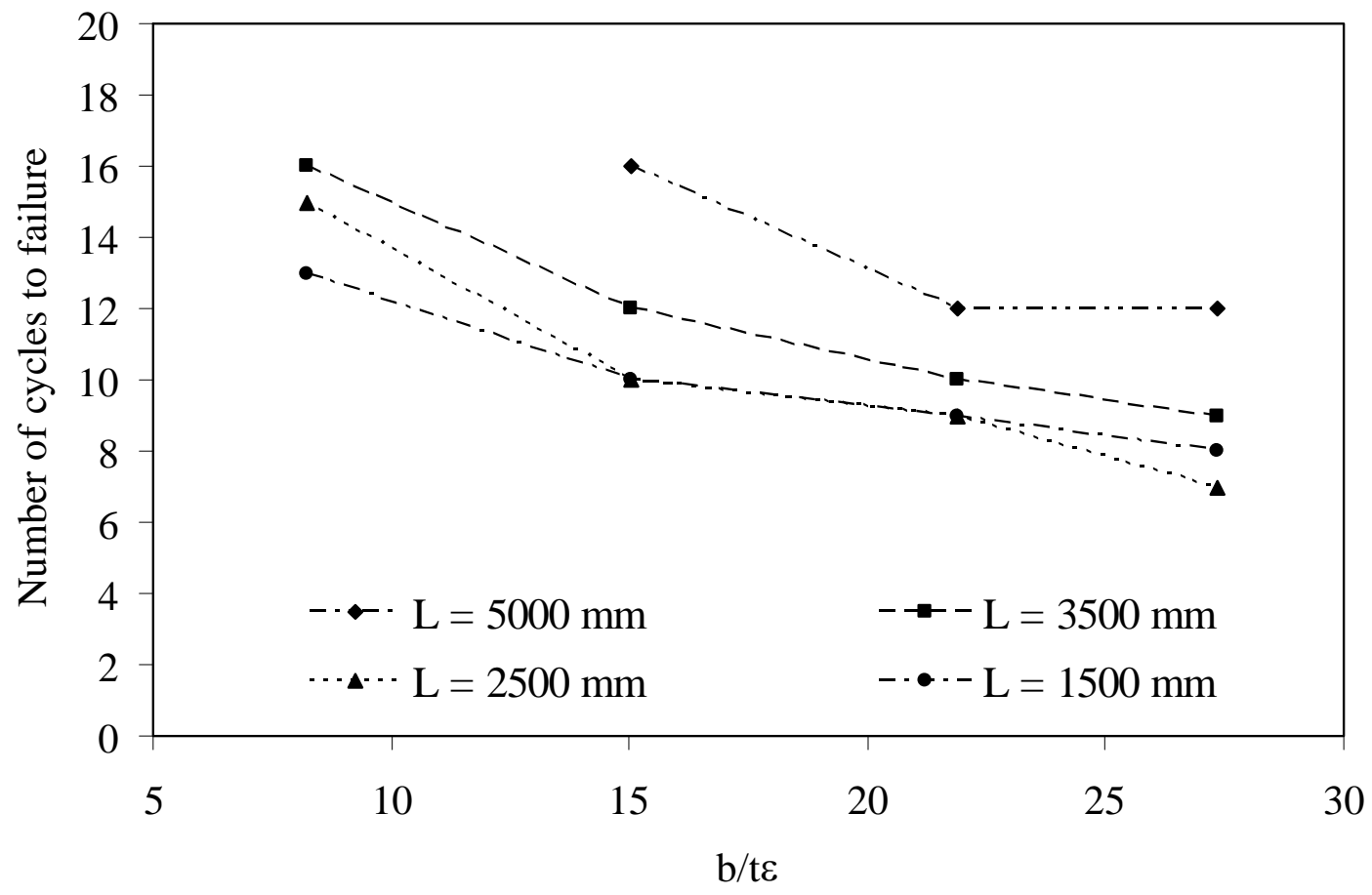

Figure 20. Relationship between local slenderness and number of cycles to failure of all specimens in the current parametric studies 


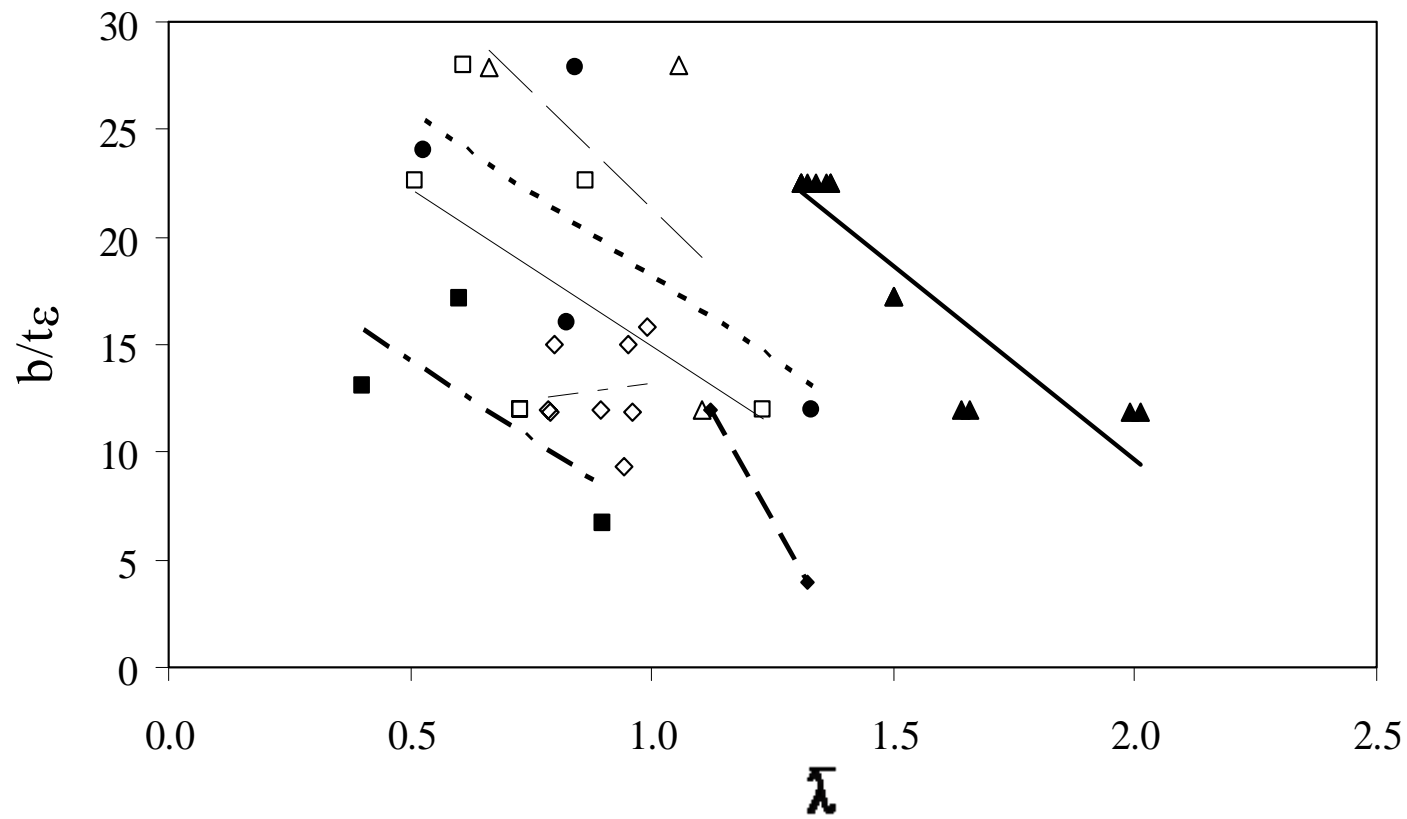

\footnotetext{
_Archambault et al. (1995) — - Black et al. (1980)

- m. Goggins et al. (2006)

Gugerli (1982)

$\square$ Lee and Goel (1987)

--- - -Liu (1987)

-.- $\diamond$.Shaback (2001)
}

Figure 21. Global and local slenderness of specimens tested in experimental programmes, from which the importance of the slenderness parameters respectively cannot be isolated and identified separately

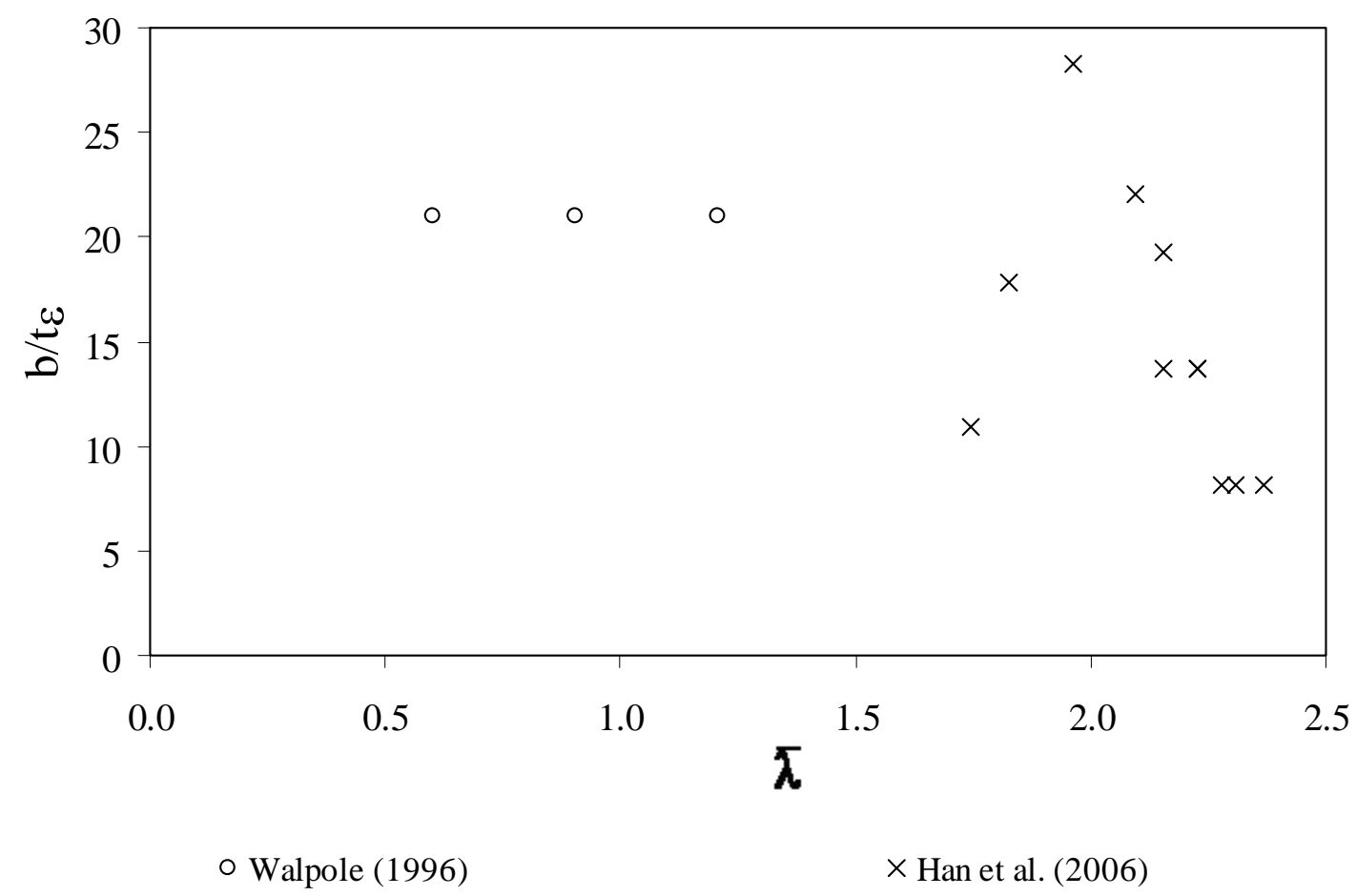

Figure 22. Global and local slenderness of specimens tested in experimental programmes, from which the importance of the slenderness parameters respectively can be isolated and identified separately 


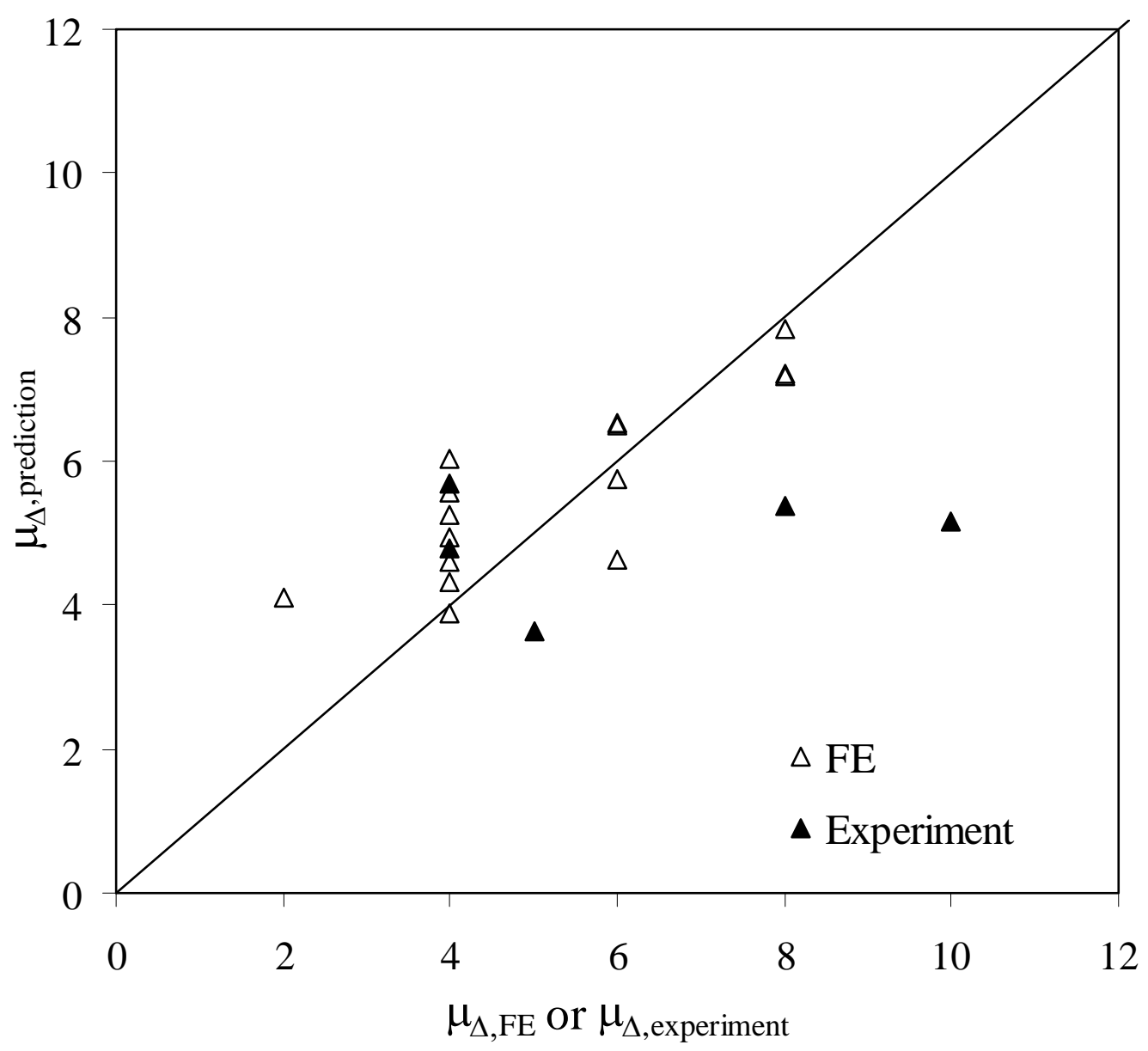

Figure 23. Comparison between the predicted values of displacement ductility from the proposal in the current study and the values obtained from FE models and experiments 
Table 1. Monotonic tensile material properties

\begin{tabular}{l|c|ccc}
\hline Specimen & $\begin{array}{c}\text { Young's } \\
\text { modulus, E } \\
\left(\mathrm{N} / \mathrm{mm}^{2}\right)\end{array}$ & $\begin{array}{c}\text { Yield strength / } \\
0.2 \% \text { proof } \\
\text { stress, fy } \\
\left(\mathrm{N} / \mathrm{mm}^{2}\right)\end{array}$ & $\begin{array}{c}\text { Ultimate } \\
\text { tensile } \\
\text { strength, } \mathrm{fu}_{\mathrm{u}} \\
\left(\mathrm{N} / \mathrm{mm}^{2}\right)\end{array}$ & $\begin{array}{c}\text { Percentage } \\
\text { elongation at } \\
\text { fracture, } \\
\varepsilon \mathrm{L}(\%)\end{array}$ \\
\hline $60 \times 60 \times 3-\mathrm{CS}-\mathrm{HR}$ & 215150 & 458 & 555 & 37 \\
$40 \times 40 \times 3-\mathrm{CS}-\mathrm{HR}$ & 219610 & 478 & 555 & 31 \\
\hline $60 \times 60 \times 3-\mathrm{CS}-\mathrm{CF}$ & 207430 & 361 & 402 & 49 \\
$40 \times 40 \times 4-\mathrm{CS}-\mathrm{CF}$ & 201640 & 410 & 430 & 38 \\
$40 \times 40 \times 3-\mathrm{CS}-\mathrm{CF}$ & 212910 & 451 & 502 & 24 \\
\hline $60 \times 60 \times 3-\mathrm{SS}-\mathrm{CF}$ & 197730 & 483 & 745 & 58 \\
$50 \times 50 \times 3-\mathrm{SS}-\mathrm{CF}$ & 197960 & 552 & 798 & 59 \\
$60 \times 40 \times 3-\mathrm{SS}-\mathrm{CF}$ & 191690 & 538 & 753 & 58 \\
\hline
\end{tabular}


Table 2. Verification of FE models

\begin{tabular}{|c|c|c|c|c|}
\hline \multirow{3}{*}{ Specimen identification } & \multicolumn{4}{|c|}{ Number of cycles to } \\
\hline & \multicolumn{2}{|c|}{$\begin{array}{c}\text { local } \\
\text { buckling }\end{array}$} & \multicolumn{2}{|c|}{ fracture } \\
\hline & Test & $\mathrm{FE}$ & Test & $\mathrm{FE}$ \\
\hline $60 \times 60 \times 3 \times 2050-C S-H R$ & 7 & 8 & 10 & 9 \\
\hline $40 \times 40 \times 3 \times 2050-\mathrm{CS}-\mathrm{HR} * *$ & 15 & 9 & 18 & 12 \\
\hline $40 \times 40 \times 3 \times 1250-\mathrm{CS}-\mathrm{HR}$ & 8 & 8 & 11 & 10 \\
\hline $60 \times 60 \times 3 \times 2050-\mathrm{CS}-\mathrm{CF}$ & 7 & 5 & 10 & 8 \\
\hline $40 \times 40 \times 4 \times 2050-\mathrm{CS}^{-C F} *$ & - & 11 & 11 & 13 \\
\hline $40 \times 40 \times 3 \times 2050-C S-C^{*}$ & 5 & 8 & 10 & 10 \\
\hline $40 \times 40 \times 3 \times 1250-\mathrm{CS}-\mathrm{CF}^{* *} *$ & 8 & 6 & 10 & 8 \\
\hline $60 \times 60 \times 3 \times 2850-\mathrm{SS}-\mathrm{CF}$ & 8 & 8 & 10 & 10 \\
\hline $50 \times 50 \times 3 \times 2850-\mathrm{SS}-\mathrm{CF}$ & 12 & 10 & 14 & 12 \\
\hline $60 \times 40 \times 3 \times \times 2850-\mathrm{SS}-\mathrm{CF}^{*}$ & - & 9 & 10 & 11 \\
\hline $60 \times 60 \times 3 \times 2050-\mathrm{SS}-\mathrm{CF}^{* *} *$ & 8 & 8 & 9 & 9 \\
\hline $50 \times 50 \times 3 \times 2050-\mathrm{SS}-\mathrm{CF}$ & 8 & 8 & 10 & 10 \\
\hline $60 \times 40 \times 3 \times 2050-S S-C F$ & 8 & 8 & 11 & 10 \\
\hline $60 \times 60 \times 3 \times 1250-\mathrm{SS}-\mathrm{CF}$ & 8 & 8 & 10 & 10 \\
\hline $50 \times 50 \times 3 \times 1250-\mathrm{SS}-\mathrm{CF}$ & 8 & 8 & 10 & 9 \\
\hline $60 \times 40 \times 3 \times 1250-\mathrm{SS}-\mathrm{CF}$ & 6 & 5 & 10 & 9 \\
\hline $40 \times 40 \times 2.5 \times 1100-\mathrm{CS}-\mathrm{CF}^{* * *}$ & - & 8 & 14 & 9 \\
\hline $50 \times 25 \times 2.5 \times 1100-\mathrm{CS}-\mathrm{CF} * * *$ & - & 7 & 17 & 9 \\
\hline $150 \times 100 \times 6 \times 2704-\mathrm{CS}-\mathrm{CF}^{* * * *}$ & - & 5 & 7 & 6 \\
\hline
\end{tabular}

$*$ Fracture at annealed material close to the weld

** Small cracks at annealed material close to the weld but fracture at mid-length *** Tests results from Goggins et al. (2006) and Walpole (1996) where number of cycles when local buckling occurred was not reported 
Table 3. A summary of results in the current parametric studies

\begin{tabular}{|c|c|c|c|c|c|c|c|c|c|}
\hline \multirow{2}{*}{ Specimen identification } & \multirow{2}{*}{$\mathrm{b} / \mathrm{t} \varepsilon$} & \multirow{2}{*}{$\bar{\lambda}$} & \multicolumn{2}{|c|}{$\begin{array}{l}\text { Cycle at which } \\
\text { buckling begins }\end{array}$} & \multicolumn{4}{|c|}{ Number of cycles to failure } & \multirow{2}{*}{$\mu_{\Delta}$} \\
\hline & & & Global & Local & $\begin{array}{l}\text { SP } \\
\text { avg }\end{array}$ & $\begin{array}{l}\text { SPN } \\
\text { avg }\end{array}$ & $\begin{array}{c}\text { SP } \\
\text { peak }\end{array}$ & $\begin{array}{l}\text { SPN } \\
\text { peak }\end{array}$ & \\
\hline $60 \times 60 \times 6 \times 5000-\mathrm{CS}-\mathrm{CF} *$ & 8.2 & 1.78 & - & - & - & - & - & - & - \\
\hline $60 \times 60 \times 4 \times 5000-C S-C F$ & 15.1 & 1.69 & 2 & 14 & 16 & 16 & 15 & 16 & 8 \\
\hline $60 \times 60 \times 3 \times 5000-\mathrm{CS}-\mathrm{CF}$ & 21.9 & 1.63 & 2 & 11 & 12 & 13 & 12 & 12 & 6 \\
\hline $60 \times 60 \times 2.5 \times 5000-\mathrm{CS}-\mathrm{CF}$ & 27.4 & 1.63 & 2 & 8 & 12 & 12 & 10 & 11 & 6 \\
\hline $60 \times 60 \times 6 \times 3500-C S-C F$ & 8.2 & 1.25 & 3 & 14 & 16 & 17 & 15 & 16 & 8 \\
\hline $60 \times 60 \times 4 \times 3500-\mathrm{CS}-\mathrm{CF}$ & 15.1 & 1.18 & 3 & 11 & 12 & 13 & 12 & 12 & 6 \\
\hline $60 \times 60 \times 3 \times 3500-C S-C F$ & 21.9 & 1.14 & 3 & 8 & 10 & 10 & 9 & 10 & 4 \\
\hline $60 \times 60 \times 2.5 \times 3500-\mathrm{CS}-\mathrm{CF}$ & 27.4 & 1.14 & 3 & 7 & 9 & 9 & 9 & 9 & 4 \\
\hline $60 \times 60 \times 6 \times 2500-C S-C F$ & 8.2 & 0.89 & 4 & 11 & 15 & 15 & 14 & 15 & 8 \\
\hline $60 \times 60 \times 4 \times 2500-\mathrm{CS}-\mathrm{CF}$ & 15.1 & 0.84 & 4 & 8 & 10 & 11 & 10 & 11 & 4 \\
\hline $60 \times 60 \times 3 \times 2500-C S-C F$ & 21.9 & 0.82 & 4 & 7 & 9 & 9 & 9 & 9 & 4 \\
\hline $60 \times 60 \times 2.5 \times 2500-\mathrm{CS}-\mathrm{CF}$ & 27.4 & 0.81 & 4 & 5 & 7 & 8 & 7 & 7 & 2 \\
\hline $60 \times 60 \times 6 \times 1500-\mathrm{CS}-\mathrm{CF}$ & 8.2 & 0.53 & 5 & 10 & 13 & 13 & 12 & 13 & 6 \\
\hline $60 \times 60 \times 4 \times 1500-C S-C F$ & 15.1 & 0.51 & 5 & 8 & 10 & 11 & 9 & 11 & 4 \\
\hline $60 \times 60 \times 3 \times 1500-\mathrm{CS}-\mathrm{CF}$ & 21.9 & 0.49 & 5 & 6 & 9 & 9 & 8 & 9 & 4 \\
\hline $60 \times 60 \times 2.5 \times 1500-C S-C F$ & 27.4 & 0.49 & 5 & 5 & 8 & 9 & 7 & 8 & 4 \\
\hline
\end{tabular}

* Analysis has not been completed due to numerical difficulty. 